\title{
Cross-Border Asset Holdings and Comovements in Sovereign Bond Markets*
}

\author{
Hossein Asgharian, Lu Liu and Marcus Larsson ${ }^{\S}$
}

March, 2018

\begin{abstract}
We analyze the importance of different asset holdings for the interdependence of the yield curves in the Euro area using a spatial VAR model. We find that the cross-border holdings of long-term debt and bank lending are important for the interdependence. We also find that comovement in the Euro area declines after 2008. We show that this decline is not related to the difference among countries in reacting to shocks from the US during the financial crisis. Rather, it largely reflects the segmentation between GIIPS and non-GIIPS countries. Our analysis of dispersion in sovereign-CDS-spread term structure shows that the differential in sovereign creditworthiness in the Euro area is a main driver of the yield-curve divergence after 2008.
\end{abstract}

Keywords: yield-curve factors, cross-border asset holding, spatial dependence, Euro bond markets, sovereign credit default swap

JEL codes: E43, G15, C31

\footnotetext{
${ }^{*}$ We thank Magnus Dahlquist, Jean Imbs, Stefan Mittnik, Lorenzo Pozzi, Konstantinos Tolikas, and participants at CEQURA Conference on Advances in Financial and Insurance Risk Management 2014, Financial Management Association European Conference 2015, International Finance and Banking Society's annual meeting 2015, and World Finance Conference 2016. We gratefully acknowledge funding from the Swedish Research Council and Torsten Söderberg Foundation.

$\S$ Hossein Asgharian, Department of economics and Knut Wicksell Centre for Financial Studies, P.O. Box 7082, S22007 Lund, Sweden. Email: Hossein.Asgharian@nek.lu.se. Lu Liu, Stockholm Business School, Stockholm University, S-106 91 Stockholm, Sweden. Email: Lu.Liu@sbs.su.se. Marcus Larsson, Senior Quantitative Analyst, Handelsbanken, Stockholm, Sweden. Email: mala99@ handelsbanken.se.
} 


\section{Introduction}

The common currency of the Economic and Monetary Union (EMU) eliminates exchange-rate risk and reduces cross-border transaction costs in the union. This should enhance the possibilities of crossborder diversification and asset holding, which in turn should increase financial-market comovements among countries in the union. One important aspect of the integration of Euro-area countries is comovement of their interest-rate markets. Interest rates form a transmission channel between the monetary policy, real activity, inflation, and asset prices and can, therefore, signal future economic activity.

In this paper, we analyze the interaction of the government-bond yield curves among Euro-area countries. We address two main research questions. First, we investigate to what extent crossborder asset holdings are important for the comovement of government-bond yields. Second, we analyze how the harmonization among yields of Euro-area countries has evolved over time.

We develop an international model for yield curves and their comovement. Specifically, by using spatial econometrics, we extend the vector autoregressive (VAR) model of the yield curve proposed by Diebold et al. (2006), which consists of the three yield-curve latent factors (level, slope, and curvature), estimated in the Nelson and Siegel (1987) tradition, and macroeconomic variables. Our model can capture contemporaneous cross-country interactions in the yield-curve factors associated with proximities among countries. We use different types of cross-border asset holdings to measure countries' proximities, as cross-border asset holdings proxy the extent of cross-border financial transactions, which create possibilities for interest-rate parity to hold. In this manner, we are able to analyze not only the level of yield curve comovement, but also to what extent cross-border asset holdings are important for the comovement. Our approach has a number 
of advantages compared to simpler correlation-based approaches. First, it is not purely bilateral, but it captures the relationships between one market and all other markets at once. Hence, our approach is particularly suitable for examining global or regional market comovement. Second, this approach allows us to capture each market's relative importance for other markets and thus for the comovement. Third, when analyzing how shocks in one market affect other markets, this approach takes into account feedback effects that may amplify the impact of the shocks. The dynamic nature of this approach suits the purpose for analyzing interaction between markets.

We find strong evidence that cross-border holdings of long-term debt and bank lending are important for the systematic dependence in yield curves among Euro-area countries, whereas holdings of short-term debt and equity are not. This result reflects the amount of holdings in different asset types and the assets' intrinsic roles for interest-rate markets. Our study of the degree of integration over time shows that the degree of comovement in the Euro area declines considerably after 2008. This decline is the most marked for slope, reflecting an increased dispersion in risk premium. We find that the decline in integration is not related to differences among countries' reactions to outside shocks from the US during the financial crisis; it largely reflects the segmentation between Greece, Ireland, Italy, Portugal and Spain (GIIPS) and nonGIIPS countries. Furthermore, we investigate the role of differences in credit risk for divergence by extending our model and allowing the level of comovement to be a function of cross-country dispersion in sovereign credit risk. We find that comovement of the yield curve decreases significantly as the cross-country dispersion in the term structure of the credit-default-swap (CDS) premium rises.

Our study draws on two strands of literature, namely, the literature on interest-rate convergence in the Euro area and the macrofinance literature on yield curves. The first strand of literature looks 
mainly at a certain point on the yield curve in the Euro area, especially long-term instruments such as 10-year government bonds (see e.g., Codogno et al., 2003; Manganelli and Wolswijk, 2009; Bernoth and Erdogan, 2012; Antonakakis and Vergos, 2013; Costantini et al., 2014). There are a few exceptions: Baele et al. (2004) show that local yields with various maturities of all Euro-area countries become more integrated with those of Germany and France in the period 1999-2003 than in 1995-1998. The degree of integration is higher in the 10-year maturity segment than in the two- and five-year segments. A more recent study by Ehrmann et al. (2011), uses yields of maturities between two and 10 years, ignoring the very short-end maturities, to investigate the comovement of the yields of Italy, Spain, France and Germany from 1997 to 2008. The paper looks at unconditional correlation of the yields and the contribution of first and second principal components (level and slope) to the cross-sectional variation of yields across the countries. The time period considered in previous studies is mostly limited to the period before the euro debt crisis starting in 2009.

Our paper also builds on studies that model the whole yield curve based on latent factors (e.g., Nelson and Siegel, 1987; Knez et al., 1994; Duffie and Kan, 1996). The latent factors of the yield curve are usually indicated by level, slope, and curvature (see, e.g., Litterman and Scheinkman, 1991; Dai and Singleton, 2000), which describe the factors' effect on the yield-curve shape. In general, level represents the overall level of the interest rates in the market. The slope of the yield curve reflects the market expectations of the future economy and the required bond risk premiums. ${ }^{1}$

\footnotetext{
${ }^{1}$ Laurent (1988), Estrella and Hardouvelis (1991), Estrella and Mishkin (1998), and Hamilton and Kim (2002), show the predictability of slope for economic growth. Mishkin (1990a) and Mishkin (1990b), among others, show empirically that slope is a significant predictor of inflation. Estrella (2005) provides an analytical rational expectations model that explicitly relates the yield-curve slope to expectations of real activity and inflation.
} 
Lund and Christensen (2005), for example, suggest that the curvature of the yield curve is related to interest-rate volatility. Recent studies have also explicitly related the latent factors to such macroeconomic variables as real activity, inflation, and monetary policy (see, e.g. Ang and Piazzesi, 2003; Diebold et al., 2006; Dewachter and Lyrio, 2006; Hördahl et al., 2006; Wu, 2006; Evans and Marshall, 2007). This macrofinance strand of the literature typically studies a specific country and ignores cross-border interactions of yield-curve factors. An important exception is Diebold et al. (2008) study, which constructs a hierarchical dynamic factor model in which country yields are related to country factors, and country factors to global factors. Also, Abbritti et al. (2013) establish a relationship between the yield-curve level and a global factor on expected inflation using a panel data approach.

To our knowledge, this paper is the first analysis of the importance of cross-border asset holdings for the international dependence of the yield curves. Our spatial VAR model provides insights into the mechanism of yield-curve interactions among economies. We contribute to the literature by providing evidence for integration of the whole yield curve rather than just certain points on the curve, bridging the macrofinance literature on yield curves and the literature on government-bondyield integration. In addition, we enrich spatial econometric models by allowing the spatial correlation parameter to vary with exogenous economic variables.

The remainder of our paper is organized as follows. Section 2 presents our model and describes the spatial econometric methodology. Section 3 contains the variable selection and data description. In Section 4, we present our results, and Section 5 concludes the paper. 


\section{The Empirical Model}

We develop an international model for yield curves using latent factors and macroeconomic variables. Our model is an extension of the domestic VAR model by Diebold et al. (2006). The domestic model for each country $i$ relates the value of each factor $k$ at time $t, f_{\text {kit }}$, to the lagged values of all the factors, including the factor $k$ itself, in the same country:

$$
f_{k i t}=\alpha_{k}+\sum_{l=1}^{K} \beta_{k l} f_{l i, t-1}+\varepsilon_{k i t}
$$

$$
\text { for } k=1, \ldots, K, l=1, \ldots, K, i=1, \ldots, N \text { and } t=1, \ldots, T \text {. }
$$

The factors consist of the three latent factors of yield curves-level, slope, and curvature-and three macroeconomic variables - industrial production growth, inflation, and policy rateyielding six equations. The latent factors are constructed using the Nelson-Siegel approach (see Nelson and Siegel, 1987).

We extend the domestic model in equation (1) to an international factor model by using spatial Durbin regression. Specifically, our model relates the value of each factor for a country, not only to the lagged values of all the factors in that country, but also to the contemporaneous values of that factor and the lagged values of all the factors in all the other countries.

$$
f_{k i t}=\alpha_{k}+\rho_{k} \sum_{j \neq i}^{N} w_{i j t} f_{k j t}+\sum_{l=1}^{K} \beta_{k l} f_{l i, t-1}+\sum_{l=1}^{K} \theta_{k l} \sum_{j \neq i}^{N} w_{i j t} f_{l j, t-1}+\varepsilon_{k i t}
$$

The parameter $\rho_{k}$ measures the degree of spatial dependence between factor $k$ of different countries, $\beta_{k l}$ defines the effect of the one-period-lagged value of factor $l$ on the current value of factor $k$, and $\theta_{k l}$ measures the weighted cross-border effect of the one-period lag of factor $l$ on factor $k$. Our model weights the effect of each country $j$ on country $i$ by country $j$ 's relative 
closeness to country $i$, which we denote by $w_{i j}$. We will show later that this model can capture the cross-border transmissions of shocks in both the dependent variable and the explanatory variables.

Since we have both cross-sectional and time-series variations in our data, we use panel data specification with cross-sectional fixed-effect and year dummies. The model for each factor $k$ at time $t$ can be expressed in the matrix formation as

$$
\boldsymbol{f}_{k t}=\rho_{k} \boldsymbol{W}_{t} \boldsymbol{f}_{k t}+\boldsymbol{X}_{t} \boldsymbol{\beta}_{k}+\boldsymbol{W}_{t} \boldsymbol{X}_{t} \boldsymbol{\theta}_{k}+\boldsymbol{D} \boldsymbol{\alpha}_{k}+\boldsymbol{D}^{y} \boldsymbol{\tau}_{k}+\boldsymbol{\varepsilon}_{k t}
$$

where the vector $\boldsymbol{f}_{k t}$ contains $N$ observations of the factor $k$ at time $t, \boldsymbol{X}_{t}$ is an $N \times K$ matrix containing the lagged observations (one lag) of all $K$ factors (including the factor $k$ ), and $\boldsymbol{\beta}_{k}$ and $\boldsymbol{\theta}_{k}$ are the corresponding $K \times 1$ vectors of parameters in the model for factor $k$. $\boldsymbol{W}_{t}$ is the $N \times N$ time-varying spatial weight matrix. $\boldsymbol{W}_{t} \boldsymbol{f}_{k t}$ is called the spatial lag, as opposed to autoregressive lag. $\boldsymbol{D}$ is an $N \times N$ matrix containing a $N \times 1$ vector of ones and $N-1$ country-specific dummy variables, and $\boldsymbol{\alpha}_{k}$ is an $N \times 1$ vector containing the global constant and $N-1$ fixed-effect parameters. $\boldsymbol{D}^{y}$ is an $N \times(Y-1)$ matrix containing $Y-1$ year-specific dummies, where $Y$ is the number of years, and $\boldsymbol{\tau}_{k}$ is the $(Y-1) \times 1$ parameter vector for year fixed effects. $\boldsymbol{\varepsilon}_{k}$ is an $N \times 1$ vector of idiosyncratic error terms. To estimate the model in equation (3), we use a Bayesian estimation method (see, e.g., LeSage, 1997), which allows for heteroskedastic errors. ${ }^{2}$

We use the cross-border holdings of debt and equities and cross-border bank lending to define the weight matrix $\boldsymbol{W}_{t}$. The elements in this matrix show the relative closeness of the countries to each other. More specifically, the element in row $i$ and column $j$ of the matrix shows the amount invested

\footnotetext{
${ }^{2}$ For the Bayesian estimation, we use the matlab codes provided by LeSage on http://www.spatialeconometrics.com/. Readers may refer to (LeSage, 1997) for the information about prior and posterior distributions of the parameters.
} 
by country $i$ in country $j$ in period $t$ relative to the total amount invested by country $i$ in all the countries included to our sample. This element is therefore a measure of the exposure of the country $i$ to shocks in country $j$.

The model in equation 3 can be written in reduced form as

$$
\boldsymbol{f}_{k t}=\left(\boldsymbol{I}_{N}-\rho_{k} \boldsymbol{W}_{t}\right)^{-1}\left(\boldsymbol{X}_{t} \boldsymbol{\beta}_{k}+\boldsymbol{W}_{t} \boldsymbol{X}_{t} \boldsymbol{\theta}_{k}+\boldsymbol{D} \boldsymbol{\alpha}_{k}+\boldsymbol{D}^{y} \boldsymbol{\tau}_{k}+\boldsymbol{\varepsilon}_{k t}\right) .
$$

If $\rho_{k}$, which measures the degree of spatial dependence between factor $k$ of various countries, is different from zero, $\left(\boldsymbol{I}_{N}-\rho_{k} \boldsymbol{W}_{t}\right)^{-1}$ is not an identity matrix, thus any unexpected shock $\varepsilon$ to factor $k$ of one country will trigger movements in that factor of the spatially related countries, which in turn will feed back to the country itself, thereby amplifying the shock's effect. Furthermore, changes in the explanatory variables $\boldsymbol{X}$ in one country may affect the dependent variable in the same country and its spatially related countries (see Anselin, 2006; LeSage and Pace, 2009). The values of the parameter vector $\boldsymbol{\beta}_{k}$ are interpreted as average immediate effects of changes in the explanatory variables on the dependent variables of the same country (see, e.g., Kelejian et al., 2006). The effects are termed "immediate," as they do not include feedback effects among countries caused by spatial linkages. If $\rho_{k}$ is significant and positive, each explanatory variable will indirectly affect the dependent variable of other countries due to spillover among dependent variables of spatially related countries. Also, the immediate effect $\boldsymbol{\beta}_{k}$ on the country itself will be increased by spatial feedback. Our model can also capture the direct effect of every explanatory variable on the dependent variable of other countries thanks to the presence of $\boldsymbol{W}_{t} \boldsymbol{X}_{t} \boldsymbol{\theta}_{k}$. If $\boldsymbol{\theta}_{k}$ is different from zero, changes in the explanatory variables of one country will directly affect the dependent variable of other countries. The effects may well spillover to other countries and become amplified by spatial feedback. 
As mentioned earlier, $\boldsymbol{\beta}_{k}$ and $\boldsymbol{\theta}_{k}$ are interpreted as the immediate effects of a change in the explanatory variables and not as the total marginal effect. To derive the total marginal effect, we express equation (4) in the following form. For the sake of simplicity, index $k$ is suppressed.

$$
\begin{gathered}
\boldsymbol{f}_{t}=\sum_{l=1}^{K} \boldsymbol{V}_{t}\left(\beta_{l} \boldsymbol{I}_{N}+\theta_{l} \boldsymbol{W}_{t}\right) \boldsymbol{x}_{l t}+\boldsymbol{V}_{t} \boldsymbol{D} \boldsymbol{\alpha}+\boldsymbol{V}_{t} \boldsymbol{D}^{y} \boldsymbol{\tau}+\boldsymbol{V}_{t} \boldsymbol{\varepsilon}_{t} \\
=\sum_{l=1}^{K} \boldsymbol{S}_{l t} \boldsymbol{x}_{l t}+\boldsymbol{V}_{t} \boldsymbol{D} \boldsymbol{\alpha}+\boldsymbol{V}_{t} \boldsymbol{D}^{y} \boldsymbol{\tau}+\boldsymbol{V}_{t} \boldsymbol{\varepsilon}_{t}
\end{gathered}
$$

where $\boldsymbol{V}_{t}=\left(\boldsymbol{I}_{N}-\rho \boldsymbol{W}_{t}\right)^{-1}$ and $\boldsymbol{S}_{l t}=\boldsymbol{V}_{t}\left(\beta_{l} \boldsymbol{I}_{N}+\theta_{l} \boldsymbol{W}_{t}\right)$. It is important to know that $\boldsymbol{V}_{t}$ can be written as a geometric series $\boldsymbol{I}_{N}+\rho \boldsymbol{W}_{t}+\rho^{2} \boldsymbol{W}_{t}^{2}+\cdots$. The term $\rho \boldsymbol{W}_{t}$ captures the immediate effect of a unit shock to $f_{t}$ on other countries, as $\boldsymbol{W}_{t}$ describes direct asset-holding relationships. $\boldsymbol{W}_{t}{ }^{2}$ describes the asset-holding relationship of the second order: Country $i$ is related to country $j$ through investing in a third country that invests in country $j$. In the same way, $\boldsymbol{W}_{t}{ }^{3}$ is the assetholding relationship of the third order, and so on. Therefore, the higher-order terms in the geometric series, $\rho^{2} \boldsymbol{W}_{t}{ }^{2}, \rho^{3} \boldsymbol{W}_{t}^{3}, \ldots$, capture additional effects via indirect asset-holding relationships. It should also be noted that any country is also indirectly related to itself. Thus, any of the higher-order terms can also be considered a spatial feedback loop, where a shock in country $i$ affects country $j$ and country $j$ feeds back to country $i$ directly as well as through a longer path from $j$ to other countries and back to $i$. In a stationary spatial system, the feedback effect becomes smaller as the order of the loop increases. This dynamic process reaches a steady state within each time period $t$.

The immediate effect (i.e. the effect without considering feedback) of a shock to $f_{t}$ in country $j$ on $f_{t}$ of country $i$ at time $t$ is given by $V_{i j, t}^{*}$, which is the element in row $i$ and column $j$ of 


$$
\boldsymbol{V}_{t}^{*}=\rho \boldsymbol{W}_{t} .
$$

The total or marginal effect, of a shock to $f_{t}$ in country $j$ on $f_{t}$ of country $i$ at time $t$ is given by $V_{i j, t}$, which is the element in row $i$ and column $j$ of

$$
\boldsymbol{V}_{t}=\left(\boldsymbol{I}_{N}-\rho \boldsymbol{W}_{t}\right)^{-1} .
$$

\section{Variable Selection and Data}

This section provides a detailed description of the yield-curve factors, macroeconomic factors, and selected measures of integration between markets. Our sample includes 11 Euro-area countries and the US (see Table 1). We use monthly data from December 2001 to December 2012 for the yield-curve and macroeconomic factors and yearly data from 2001 to 2011 for the integration measures. Our sample starts from December 2001 because statistics on cross-border holdings of equities and debts are not reported before this time.

\subsection{Yield curve latent factors}

We use the Nelson and Siegel (1987) approach to construct the latent factors, level, slope and curvature. More specifically, we estimate the following cross-sectional regression for each month t, starting in January 2002 and ending in December 2012, with the least square method.

$$
y_{m t}=b_{0 t}+b_{1 t} \frac{1-\exp \left(-\frac{m}{\lambda}\right)}{\frac{m}{\lambda}}+b_{2 t}\left(\frac{1-\exp \left(-\frac{m}{\lambda}\right)}{\frac{m}{\lambda}}-\exp \left(-\frac{m}{\lambda}\right)\right)+e_{m t}
$$

where $y_{m t}$ is the interest rate with maturity $m$ at time $t$. The parameter $\lambda$ is the decay factor, which takes values between zero and one, where a small value corresponds to a slow decay. We use a grid search to find the value of $\lambda$ that minimizes the sum of the squared residuals for each crosssectional regression. The estimated parameters $b_{0 t}, b_{1 t}$ and $b_{2 t}$ are used as the measure of the latent 
factors, level, slope and curvature, respectively. We use yield for government bills and bonds with all available maturities ranging from three months to 15 years. Since $b_{1 t}$ has the highest/lowest loading at the shortest/longest maturities, it is negatively related to the slope factor. Therefore, we reverse the sign of all estimated values of $b_{1 t}$ before using them in the subsequent estimation steps. It must also be noted that the parameter $b_{2 t}$ has its highest loading on middle-term maturities. Consequently, a higher value of $b_{2 t}$ implies a more concave (or less convex) yield curve.

The data on yields are obtained from Bloomberg. ${ }^{3}$ Maturities include 3, 6, 9, 12, 18, 24, 36, 48, $60,72,84,96,108,120$, and 180 months. Countries in our sample do not have data available for all maturities, and the number of available maturities changes over time. Therefore, we use all the available maturities from 3 to 180 months for each country in each month to estimate the factors. We choose to restrict the long end of the curve to 15 years, because 15 years is the longest maturity for which data is available for all the countries in our sample. For bonds with maturity longer than 15 years, term to maturity differs considerably across countries. For example, 50 years is the longest available maturity for Austria and France, but 30 years is the longest in many other countries. Using the part of the curve exceeding 15 years may affect the cross-country comparability of our estimated yield-curve shape. Panel A of Table 1 summarizes the available data and goodness of fit for the Nelson-Siegel estimations. For 8 out of 11 Euro area countries, we have at least 10 maturities in each month to estimate the three factors. For each country-month estimation with less than five available maturities (only Greece and for only 10 months, around $0.6 \%$ of all estimations), we assume that the shape of the yield curve does not change from the previous month and use the lagged values of the estimated factors. As shown by the monthly

3 Yield for a specific maturity, at the end of each month, is calculated with a built-in function in Bloomberg using the cashflows and the prices of bonds with maturities closest to the target maturity. 
averages of the fitting error variances and the $R^{2}$ values, our estimation of the factors fits the data well.

\subsection{Macroeconomic factors}

Following Diebold et al. (2006), we use three key macroeconomic variables: real economic activity, inflation rate, and monetary policy rate. These variables are also widely considered important economic fundamentals in other related literature (e.g., Kozicki and Tinsley, 2001; Dewachter and Lyrio, 2006; Rudebusch and Wu, 2008). Manufacturing capacity utilization used by Diebold et al. (2006) to represent real activity is not available for all the countries in our sample. Instead, we use industrial production growth, which is available for all the countries in our sample and reported at the monthly basis. We calculate yearly inflation rates as the average changes in the consumer price index (CPI) for every month of the year compared with the respective month in the preceding year. Monetary policy rate is the monthly policy rate of the European Central Bank for the Euro-area countries and the monthly federal funds rate. Data on CPI and policy rates are taken from national sources in DataStream. Data on monthly industrial production growth are collected from the OECD iLibrary.

\subsection{Integration measures}

We measure the closeness between countries using the total asset holdings. We also use closeness measures based on long-term and short-term debt instruments as well as equity holdings, separately, in order to analyze the contribution of different types of investment to the integration of the yield curve factors. As the banking system greatly contributes to the global systemic risk, we also measure countries' closeness using cross-border lending between banks. The relative closeness of country $j$ to country $i$ is calculated as 


$$
W_{i j, t}=\frac{\text { holding }_{i j, t}+\text { holding }_{j i, t}}{\sum_{\substack{k \neq \mathrm{i} \\ \text { holding }}, k+t}+\sum_{k \neq j}^{k=N} \text { holding }_{j k, t}}
$$

where holding $i j$ is the stock of investment holdings of country $i$ in country $j$. This ratio measures the bilateral holding between two countries relative to the total holdings of the two countries in all other countries. This measure is size-independent. In other words, it does not favor countries with a large amount of foreign investment. This helps to separate the spatial effect related to the bilateral closeness of the countries from a pure size effect. ${ }^{4}$

The data on cross-border holdings of equities and long- and short-term debt instruments are collected from the International Monetary Foundation's Coordinated Portfolio Investment Survey (CPIS). The data on the stocks of cross-border lending between banks are collected from the Bank for International Settlements' International Banking Statistics (BIS IBS). The data are on year-end stocks of international claims of domestic banks ${ }^{5}$ in individual economies on immediate borrowers. $^{6}$

${ }^{4}$ The closeness measure defined in equation (9) is a symmetric measure, which means $W_{i j, t}=W_{j i, t}$.

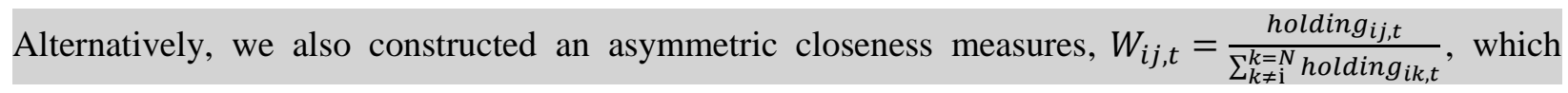
measures the holding of $i$ in $j$ relative to the total holding of $i$ in all other countries. Our main results remain the same with asymmetric closeness measures.

${ }^{5}$ Domestic banks are those with a head office in the respective reporting country. A banking system's international claims on country A are comprised of cross-border claims in all currencies booked by all offices worldwide plus nonlocal currency claims on residents of country A booked by banks' foreign affiliates located in country A.

${ }^{6}$ The statistics of claims on an ultimate-risk basis (consisting of claims on an immediate-borrower basis and net risk transfers) can provide useful supplementary information about countries' external vulnerabilities but are available for fewer countries. Hence, we choose to use the statistics of claims on an immediate-borrower basis. 
Panel B of Table 1 shows that the summary statistics of the estimated yield factors for different countries. Overall, the average level of the yield curve is larger for all the GIIPS countries compared to other Euro-area countries and the US. Most of the GIIPS countries also have significantly positive excess kurtosis and skewness, which indicates the existence of extreme interest-rate values in some periods (see the column Max for the maximum level for Greece, Ireland and Portugal).

The GIIPS countries have also a larger average slope comparing to the other countries. This reflects the relatively large spread between short- and long-term rates in the GIIPS countries due to their relatively high level of risk. The mean slope of the US is larger than that of the Euro-area countries excluding the GIIPS countries.

The sample statistics of the curvature of the yield curve shows that the mean value for Portugal and Greece is lower than that for other countries. However, judged from the minimum and maximum values, it is clear that these two countries have had periods with extreme positive and negative kurtosis, indicating that their yield curve has switched between extreme convex and concave shapes.

Furthermore, we test the stationarity of all the six factors for each country using KwiatkowskiPhillips-Schmidt-Shin test, Elliot-Rothenberg-Stock test and Phillips and Perron test. Test results in detail are available upon request. In summary, among all the variables, industrial production growth is the only one that is stationary for all the countries in our sample. Policy rate is nonstationary and unit root for all the countries while level and slope are unit roots for most countries. As for curvature and inflation, the series are unit roots in the case of some countries. Therefore, we take first differences of all the factors and used the first differences in our model in equation (3). 
For illustration, Figure 1 displays the evolution of the latent and macroeconomic factors for the US and Euro-area countries. The yield-curve levels in the US and the Euro area follow each other very closely from the beginning of the sample to 2008. The US level then drops considerably and reaches a trough at the end of 2008, one year after the start of the US recession. The drop may in part be caused by quantitative easing and decreased policy rate undertaken by the Federal Reserve to combat the credit crisis in 2008. From then on, the comovement between the US and the Euroarea yield curve levels is diminished. The US yield curve level has a decreasing trend since the recession and reaches half of its value prior to the 2012 recession. The mean of the Euro-area countries' interest-rate levels rises considerably from the beginning of 2010. Comparing the mean interest rate levels of Euro-area countries including and excluding GIIPS countries, we see that this rise is mainly caused by the increase in the GIIPS countries' interest rates, due to anxiety about their excessive national debt.

The slope factor of the Euro-area countries seems to follow that of the US until 2010. The mean value of the slopes of the Euro-area countries excluding the GIIPS remains stable, as does the slope of the US. Comparing this with the mean value of the Euro-area countries including the GIIPS shows that the average GIIPS slope rises dramatically from 2010 to 2011, indicating a sharp increase in the GIIPS sovereign risk premia. We can also see that the slopes are negatively correlated with their corresponding policy rates before 2010 when the policy rates become very low, which suggests a negative impact of the policy rate on slope. In addition, there seems also a lead-lag relationship between the federal funds rate and the European Central Bank (ECB) policy rate.

Like the slopes, the curvatures in the US and the Euro area are very similar until 2010, after which the GIIPS countries diverge from the rest of the Euro area and the US. For the Euro-area countries 
and the US, industrial production growth drops considerably during the US financial crisis. We also observe a substantial negative growth for the GIIPS countries in 2012. Additionally, the inflation rate in the Euro area, in contrast to the US inflation rate, is stable and close to the ECB's target inflation rate until the end of 2007, but it is slightly lower in the non-GIIPS countries. Unsurprisingly, the inflation rates of the Euro area and the US drop to negative values in the recession period associated with the US financial crisis and return to normal levels after that.

\section{Results and Analysis}

In this section, we first present the results of estimating our suggested model in equation (3) for the entire sample in order to see how different linkages between the countries affect interdependence in the yield-curve factors. Next, we investigate the importance of each Euro country in our sample for the comovement of the yield curve. The third subsection analyzes the degree of integration of Euro government-bond markets over time and the last subsection explores the role of credit risk for integration of the yield-curve factors.

\subsection{The importance of cross-border asset holdings for yield-curve comovement}

In this section, we analyze the estimated results of the model in equation (3). Our main purpose is to examine the importance of different cross-border asset holdings for the dependence of yieldcurve factors across countries. Since our main interest is only in the yield-curve factors, we do not report the estimation with the macroeconomic factors as dependent variables. The estimated coefficients for the estimations with the latent factors as dependent variables are presented in Table

2. The estimated coefficients for the country fixed effects and year dummies are not reported, but they are available upon request. 
We start by analyzing the estimated $\rho$ values, which show the degree of spatial dependence across countries. The first row of each panel shows the estimated $\rho$ values for different closeness measures constructed based on cross-border asset holdings. We also use a matrix with equal weights as the benchmark which assumes equal distances between any two countries. The spatial correlation is highly statistically significant for all the latent factors, over all the choices of the weight matrices. However, as pointed out in Asgharian et al. (2013), the statistical significance of spatial correlation may be caused primarily by global comovement owing to common trend, not by the selected closeness measure. If this is the case, the estimated values of $\rho$ should be large, no matter how the relative weights in the matrix $\boldsymbol{W}$ are chosen for each country. Hence, we perform a simulation analysis where we try to span the universe of closeness measures by randomly generating 5000 weight matrices and estimating the model for each matrix. This results in 5000 different estimates of $\rho$, which constitute the empirical distribution of the estimated $\rho$ values. By comparing the estimated $\rho$ for a selected closeness measure with the confidence intervals of the empirical distribution we can verify if the closeness measure is meaningful for comovement among markets or the significance of its $\rho$ is merely due to a global comovement in yields. Figure 2 compares the estimated values of the spatial coefficients, $\rho$, from the selected closeness measures (the dots) with the $99 \%$ and $95 \%$ one-sided confidence intervals of the empirical distribution of the estimated $\rho$ values from the randomly generated weight matrices. For equal weight matrix, the estimated $\rho$ values are below the $95 \%$ one-sided confidence interval for all the three factors. This suggests that assuming equal distances between all countries is not appropriate for studying yield-curve comovements. In contrast, the estimated $\rho$ values for total investment are above $99 \%$ of the onesided confidence interval for all the three factors, indicating the importance of cross-border investment for yield curve integration. However, all types of investment are not important for 
yield-curve comovements. Specifically, although statistically significant, the estimated $\rho$ values for short-term debt and the equal-weight matrix do not exceed $95 \%$ of the $\rho$ values from the randomly generated closeness measures, for any factors. This indicates that the statistical significance and large value of $\rho$ associated with these measures may primarily be caused by global comovement in interest-rate levels. The estimated $\rho$ for equity is higher than the $99 \%$ one-sided confidence interval only for the slope factor. Moreover, the estimated $\rho$ values using long-term debt and bank lending are above $99 \%$ of the $\rho$ values from the randomly generated matrices for all the three factors, which means that there exists systematic yield-curve spatial dependence through these two cross-border asset holdings.

It is possible that the holdings of short-term debt and equity by nature-perhaps due to the type of securities involved - do not affect interest-rate markets as strongly as the two other holdings do. Short-term debt involves securities with maturities less than one year, so transactions on these securities may not dramatically affect the whole term structure of the interest rates. Similarly, equity holdings do not directly imply transactions on fixed income securities. Another possible explanation for why the short-term debt and equity holdings appear unimportant to the systematic spatial dependence in yield curve is reflected by the amount of these asset holdings among Euroarea countries. Shown in Figure 3, the yearly amounts of long-term debt holding and bank lending are considerably larger than the holdings of short-term debt and equity over the whole sample period. It is possible that the amount of cross-border short-term lending and equity holding is too small to affect the comovement of interest rates and, therefore, the weight structures imposed by these two types of asset-holding cannot properly capture the comovement among the interest rates. Further, the importance of the total investment shown in Figure 2 should mostly reflect the 
contribution of the long-term debt, as the long-term debt is by far the largest part of the total investment.

It must be noted that for the level factor, the estimated $\rho$ 's with long-term debt and bank lending as the weighting matrix is only slightly higher than the $99 \%$ confidence interval, as well as $\rho$ obtained by an equally weighted matrix. Therefore, we may conclude that the level of interest rates have large comovement among all the Euro area countries and the spatial relation between the countries has only a marginal contribution to this comovement. However, for the slope and the curvature factors, the contribution of the spatial relationship, through long-term debt and bank lending, is considerable, as the estimated $\rho$ 's. are more than $10 \%$ and $25 \%$ higher than the $99 \%$ confidence intervals for slope and curvature, respectively (20\% and $60 \%$ compared to an equally weighted matrix). This may indicate that interest rates of various maturities match better between countries with larger cross-border financial transactions with each other. Hence, there is stronger comovement in the shape of the yield curve.

To illustrate the relative importance of the spatial relationship between countries, we compare the models implied yields obtained from two alternative closeness measures, bank lending and the equally weighted matrix as benchmark, by analyzing their accuracy of predicting the actual yields. We select bank lending because this matrix gives the largest spatial correlation between the Euro area countries, according to Table 2 and Figure 2. We choose two different maturities, five and 10 years, for which yield data are available for all the Euro-area countries during most of the sample period. We use two metrics for comparison: Mean square error (MAE) shows the deviation of the implied yields from the actual yield, and correlation shows how well implied yields comove with the actual yields. To obtain the implied yields, we use the reduced form of the spatial regression model (see equation 4) to obtain the implied factors, which then are used in the Nelson-Siegel 
equation to calculate the implied yield. Since the reduced form also includes one lagged factor values, we use the estimated factor values for $t=1$ and recursively calculate the implied factor values for all $t$, using the estimated parameters given in Table 2. Figure 4 shows the results of this comparison. For yields with the five-year maturity, bank lending has a lower MAE and considerably larger correlation with the actual yield for all the countries, compared to the equally weighted matrix. The result for the ten-year maturity in general confirms the better performance of bank lending, but the MAE of bank lending is larger than that of equally weighted matrix for three out of 11 countries.

In what follows, we analyze the estimated values of vectors $\boldsymbol{\beta}$ and $\boldsymbol{\theta}$, the coefficients for the explanatory variables, which consist of the lag of the dependent variable and the lagged changes in the other factors and macroeconomic variables. It must be noted that the values of $\boldsymbol{\beta}$ and $\boldsymbol{\theta}$ measure the immediate effects rather than total marginal effects, see Section 2. First, the $\beta$ associated with the lagged dependent variable is negative and statistically significant for the factors slope and curvature, regardless of the closeness measure. Since we estimate the regression on the first differences, the negative sign of this $\beta$ implies that these two factors are mean reverting. Second, the $\beta$ values for the lagged changes in the other factors show that there exist cross-factor dynamics. As in Diebold et al. (2006), we find a negative effect of lagged slope on level. We also find a positive effect of lagged curvature on level, whereas Diebold et al. (2006) do not find any significant relationship between these two variables. Furthermore, the impacts of macro factors on the yield-curve factors of the same country appear insignificant in almost all cases. To some extent, this differs from Diebold et al. (2006), which shows that lagged manufacturing capacity utilization affects slope, and that the lagged federal funds rate affects both level and slope. 
Judged from the estimates of $\boldsymbol{\theta}$, we can see that yield-curve factors in one country can directly affect factors in other countries. Furthermore, the estimated $\theta$ values for inflation are positive and significant for the level factor. This result, together with the insignificance of the estimated $\beta$ values for lagged inflation may indicate that the domestic interest-rate level reacts more quickly to the domestic inflation than to that of the other countries and, therefore, we do not observe any significant impact of the inflation of a country on the interest-rate level of that country in the next period. An alternative explanation for this is that the ECB makes monetary policy decisions based on the area-wide inflation. Hence, the short term interest rate and expectations of the short rate path should depend on the (weighted) average inflation rate of the Euro-area member countries, and the contribution of inflation rate of the country is small. ${ }^{7}$ Additionally, since the Euro-area countries have the same policy rate, the ECB rate, the value of $\theta$ for this variable is restricted to be zero and is thus not reported.

\subsection{The importance of individual countries}

In this part, we investigate the importance of each Euro country for comovement of the yield curve. We add an interaction term into the model in equation (3) to reveal how the degree of dependence on the focus country (hereby denoted as the dominant country) differs from the dependence on other countries:

$$
\boldsymbol{f}_{k t}=\rho_{k} \boldsymbol{W}_{t} \boldsymbol{f}_{k t}+\rho_{k, \mathrm{dom}} \boldsymbol{W}_{t} \boldsymbol{I}^{\mathrm{dom}} \boldsymbol{f}_{k t}+\boldsymbol{X}_{t} \boldsymbol{\beta}_{k}+\boldsymbol{W}_{t} \boldsymbol{X}_{t} \boldsymbol{\theta}_{k}+\boldsymbol{D} \boldsymbol{\alpha}_{k}+\boldsymbol{D}^{y} \boldsymbol{\tau}_{k}+\boldsymbol{\varepsilon}_{k t},
$$

where $I^{d o m}$ is a $N \times N$ matrix with the diagonal element corresponding to the dominant country equal to one and all the others equal to zero. In this case the total (i.e., marginal) effect of a shock

\footnotetext{
${ }^{7}$ We are grateful to the anonymous reviewer for this alternative explanation.
} 
to a latent factor of the dominant country $j$ on the same of factor of country $i$ at time $t$ is given by $V_{i j, t}$, which is the element in row $i$ and column $j$ of

$$
\boldsymbol{V}_{t}=\left(\boldsymbol{I}_{N}-\rho \boldsymbol{W}_{t}-\rho_{\mathrm{dom}} \boldsymbol{W}_{t} \boldsymbol{I}^{\mathrm{dom}}\right)^{-1}
$$

We perform the analysis for all three latent factors using cross-border total investment as the closeness measure. Table 3 shows the total spatial effect of each country averaged over time, $\bar{V}_{i, j}$, for different countries, where $j$ specifies the dominant country. The dominant countries are in the columns of the table. All the values are positive except for the effect of the level factor of Greece. The negative total spatial effect of Greece is due to the negative estimated spatial correlation parameter for this country, i.e. $\rho+\rho_{\text {Greece, }}$ which may reflect the divergence of the interest rate level of Greece from that of other Euro countries during the European sovereign crisis.

The last row for each latent factor shows the mean spatial effect of each dominant country on other countries, which can be used to assess the relative importance of that country. For the level factor, Germany is the most important country, while France is the most important country for the other two factors. France is affected largely by Germany, Italy and the Netherlands, while France, Italy and the Netherlands are the most important for Germany. Although our closeness measure is sizeindependent (see Section 3.3), the countries with relatively large size are the main drivers of the interest rate comovements.

For all the latent factors, the effect of a one-unit shock in a country on itself becomes larger than one in all cases except for the effect of the level factor of Greece. The reason is that, due to positive spatial dependence, a one-unit shock in a country affects other countries, which feed back positively to the country itself. In the case of Greece, the negative spatial correlation with other countries causes negative feedback and results in the effect being lower than one unit. 
As we can see in equation (11), the estimated spatial effect, $V_{i j, t}$, depends both on the cross-border asset holding, matrix $\boldsymbol{W}$, and the estimated spatial correlation, $\rho$. In Figure 5, we illustrate the relation between the cross-border total investment and the estimated spatial effects. For each country, edges point to three closest countries in terms of the volumes of total bilateral investment over the entire sample period. The size of the node for each country indicates the mean spatial effect of the country shown in Table 3. For the sake of space, we use only the effect of the level factor. France and Germany, as shown in Table 3, have the largest mean spatial effects. At the same time, they connect all other countries through large relative bilateral investment. Italy and the Netherlands, which also show large mean spatial effects, are closely connected to France and Germany reciprocally (as edges point in both directions) and to a few other countries. Acting like hubs, these four countries connect the Euro-area countries through cross-border investment and drive the comovement in interest rate level.

\subsection{Time variation in the degree of integration}

In this section, we analyze to what extent the degree of integration of Euro government bond markets has changed over time. To study the degree of integration over the years, we estimate the spatial correlation coefficient $\rho$ from the baseline model for each year from 2002 to 2012 (equation (3), without the year dummy). We present the yearly estimate and confidence interval of the spatial correlation coefficient for each latent factor, respectively, in Figure 6. The figures on the left are based on the sample with all the Euro-area countries. For brevity, we show the coefficient associated with the total investment. For the level and slope factors, the estimated $\rho$ has stable values and high statistical significance over the years between 2002 and 2007. For the curvature factor, the estimated $\rho$ is highly statistically significant and increases gradually from 2002 to 2005 . It drops considerably in 2006, but returns to its previous level in 2007. The estimates of $\rho$ values 
from 2002 to 2007 largely indicate a strong degree of integration in all the latent factors during this period. This result is in line with the Ehrmann et al. (2011) study, which finds that the monetary union has unified government bond markets using the data from 1993 to 2008.

In contrast to convergence in the period between 2002 and 2007, the degree of comovement in the Euro area starts to decline in 2008, as revealed by the decreasing trend of $\rho$ from 2008 to 2012 for all factors. The decreasing trend is so remarkable that the estimate of $\rho$ becomes insignificant at the $95 \%$ confidence interval for the level factor in year 2012, for slope from 2010 to 2012, and for curvature in 2010 and 2012. The insignificance of $\rho$ for slope in the end of the sample period may indicate an increased dispersion in risk premium across the Euro-area countries.

Our finding about the comovement among Euro government bond markets may have more than one interpretation. First, the decrease in the value of $\rho$ after year 2007 may, in this case, indicate that the Euro bond markets become less sensitive to the shocks of other Euro bond markets. Alternatively, the comovement may be related to the degree of similarity among Euro bond markets in their reactions to external common shocks. For example, the decline in comovement starting from 2008 may reflect that Euro-area countries react differently to the US financial crisis. To investigate the integration among Euro markets further, we include the yield factors and macroeconomic variables of the US in the estimation. In order to control for the influence from the US, we augment the baseline model: 


$$
\begin{gathered}
f_{k i t}=\alpha_{k}+\rho_{k, \text { Euro }} \sum_{\substack{i \in \text { Euro } \\
j \in \text { Euro }}}^{N} w_{i j} f_{k j t}+\rho_{k}^{*} \sum_{\substack{\{i \in \text { Euro,j=US }\} \cup \\
\{i=\mathrm{US}, j \in \text { Euro }\}}}^{N} w_{i j} f_{k j t}+\sum_{l=1}^{K} \beta_{k l} f_{l i, t-1} \\
+\sum_{l=1}^{K} \theta_{k l} \sum_{j \neq i}^{N} w_{i j} f_{l j, t-1}+\varepsilon_{k i t}, \\
k=1 \ldots K, i=1, \ldots N+1, j=1, \ldots N+1, t=1, \ldots T,
\end{gathered}
$$

which separates $\rho_{k \text {,Euro }}$, the spatial correlation among Euro-area countries, from $\rho_{k}^{*}$, the spatial correlation between the Euro countries and the US.

The diagrams in the middle of Figure 6 show the yearly estimates of $\rho_{\text {Euro }}$ and their confidence intervals based on the sample including the US. By comparing the trends of these estimates with those based on the sample of Euro-area countries (diagrams in the left), we can see whether the dependence among Euro-area countries is influenced by the US market. For all the factors, the trend of $\rho_{\text {Euro }}$ is similar to that of $\rho$ in the left diagrams. This suggests that divergence in the Euro area is not explained by the US influence.

Another possible reason for the divergence in the Euro area is segmentation among markets in the region. We investigate this by removing the GIIPS countries in the estimation of the baseline model (equation (3), without the year dummy), and look at the dependence among non-GIIPS countries (i.e., Austria, Belgium, Finland, France, Germany, and the Netherlands). The graphs on the right in Figure 6 show the yearly estimates of the spatial correlation coefficient and confidence intervals for the sample of non-GIIPS Euro-area countries. As for the level factor, the spatial correlation coefficient for non-GIIPS countries is statistically significant throughout the period from 2002 to 2012. After reaching the peak in 2007, the spatial correlation decreases mildly, in contrast to the 
marked decrease in the parameter for the sample including GIIPS countries shown by the graphs on the left.

The spatial correlation of slope exhibits a slight decreasing trend from 2007. However, in contrast to the spatial correlation being statistically insignificant from 2010 to 2012 for the sample including GIIPS countries (graphs on the left), the spatial correlation for non-GIIPS countries is statistically significant throughout the whole sample period. As for curvature, the trend of dependence among non-GIIPS countries looks similar to that among Euro-area countries. In all, the integration among non-GIIPS countries declines mildly, so the aforementioned divergence in the Euro area reflects largely the segmentation between GIIPS and non-GIIPS countries. It should, however, be noted that the values of the estimates are not comparable across different samples due to the different numbers of markets included. As documented in Asgharian et al. (2013), the estimated value of the spatial correlation coefficient depends on the number of related countries.

\subsection{The role of sovereign creditworthiness}

In the previous section, we showed that the degree of integration among yield factors of the Euroarea countries declined after 2008. Since investors are generally compensated with a higher premium for holding government bonds issued in a country with higher sovereign credit risk, a possible explanation for the divergence in yields is the relative change in the sovereign credit risks. ${ }^{8}$ To analyze the effect of the credit risk, we divide the government-bond yield of country $i$, $Y_{i}$, in two parts:

\footnotetext{
8 The decline of integration is not explained by exchange-rate risk, as the Euro area countries in our sample use the same currency and are subject to the same monetary policy executed by the ECB. The decline may be due to inflation-rate differential. We control for this possibility to some extent by including the lagged inflation rate of each country in the model.
} 


$$
Y_{i}=Y_{i}^{*}+P_{i}
$$

where $Y_{i}^{*}$ is the default-free part of the interest rate, which reflects the expected short rate and term premium components, and $P_{i}$ is the part associated with default risk, which includes the risk premium due to sovereign risk and the expected (actuarial) losses from default. Both $Y_{i}^{*}$ and $P_{i}$ vary over maturities. Using the traditional method, the level, slope, and curvature of the yield curve can be defined as

$$
\begin{aligned}
\boldsymbol{Y}_{\text {level }}= & \frac{1}{K} \sum_{k=1}^{K} \boldsymbol{Y}_{k}=\frac{1}{K} \sum_{k=1}^{K} \boldsymbol{Y}_{k}^{*}+\frac{1}{K} \sum_{k=1}^{K} \boldsymbol{P}_{k}=\boldsymbol{Y}_{\text {level }}^{*}+\boldsymbol{P}_{\text {level }} \quad k=1, \ldots, K \\
\boldsymbol{Y}_{\text {slope }} & =\boldsymbol{Y}_{l}-\boldsymbol{Y}_{s}=\left(\boldsymbol{Y}_{l}^{*}+\boldsymbol{P}_{l}\right)-\left(\boldsymbol{Y}_{S}^{*}+\boldsymbol{P}_{s}\right)=\left(\boldsymbol{Y}_{l}^{*}-\boldsymbol{Y}_{S}^{*}\right)+\left(\boldsymbol{P}_{l}-\boldsymbol{P}_{s}\right) \\
& =\boldsymbol{Y}_{\text {slope }}^{*}+\boldsymbol{P}_{\text {slope }} \\
\boldsymbol{Y}_{\text {curv }}= & \frac{1}{2}\left(\left(\boldsymbol{Y}_{l}-\boldsymbol{Y}_{m}\right)-\left(\boldsymbol{Y}_{m}-\boldsymbol{Y}_{S}\right)\right) \\
= & \frac{1}{2}\left(\left(\boldsymbol{Y}_{l}^{*}+\boldsymbol{P}_{l}\right)-\left(\boldsymbol{Y}_{m}^{*}+\boldsymbol{P}_{m}\right)-\left(\boldsymbol{Y}_{m}^{*}+\boldsymbol{P}_{m}\right)-\left(\boldsymbol{Y}_{S}^{*}+\boldsymbol{P}_{S}\right)\right)=\boldsymbol{Y}_{\text {curv }}^{*}+\boldsymbol{P}_{\text {curv }}
\end{aligned}
$$

where $k$ stands for a certain maturity, and $s, m$, and $l$ denote short, medium, and long maturities, respectively. The cross-sectional covariance matrix of each factor is

$$
\boldsymbol{\Sigma}_{Y_{x}}=\boldsymbol{\Sigma}_{Y_{x}^{*}}+\boldsymbol{\Sigma}_{P_{x}}+\boldsymbol{\Sigma}_{Y_{x}^{*} P_{x}} \quad \text { for } x=\text { level, slope, and curv, }
$$

where $\boldsymbol{\Sigma}_{Y_{x}}, \boldsymbol{\Sigma}_{Y_{x}^{*}}$, and $\boldsymbol{\Sigma}_{P_{x}}$ are $N \times N$ covariance matrices of $Y_{x}, Y_{x}^{*}$, and $P_{x}$, and $\boldsymbol{\Sigma}_{Y_{x}^{*} P_{x}}$ is the $N \times N$ covariance matrix of the two components of the yield across countries. Each diagonal element is the covariance between the two components of the same country. According to equation (14), the comovement in the yield curve depends on that in the risk-premium term structure. To investigate this empirically, we analyze if the degree of spatial correlation of yield curve factors is related to 
the correlation of credit-risk factors. We use cross-sectional dispersion suggested by Solnik and Roulet (2000) to measure the general correlation level in credit risk at each time point: The higher the dispersion, the lower the correlation. We follow Ang and Longstaff (2013) and use the sovereign CDS spread as the measure of sovereign credit risk. We extend the model in equation (3) by defining a time-varying spatial correlation parameter as a function of the cross-sectional dispersion in the CDS spread:

$$
\rho_{t}=\rho_{0}+\rho_{\mathrm{CDS}} \sigma_{\mathrm{CDS}, t-1}
$$

where $\sigma_{\mathrm{CDS}}$ is the cross-sectional standard deviation of the sovereign-CDS-spread level, slope, and curvature, respectively, in the regressions for yield-curve level, slope, and curvature.

A differential in sovereign creditworthiness has been suggested as an important determinant of yield differential by the previous literature (e.g. Codogno et al., 2003; Manganelli and Wolswijk, 2009; Costantini et al., 2014). However, these studies use sovereign credit ratings, debt to GDP ratio, and government budget balance to GDP as measures of a country's creditworthiness. An advantage of using sovereign CDS spread is that sovereign CDSs are traded with several maturities, ranging from one year to 10 years, revealing market view of credit risk over different horizons. Therefore, by using sovereign CDS spread, we can relate the comovement of interestrate term structure to that of risk-premium term structure.

We construct the level, slope, and curvature factors of sovereign CDS spread (in basis points), ${ }^{9}$ which correspond to the three yield-curve factors. The level factor of CDS spread is calculated as the average of CDS spreads with 10 different maturities, one to 10 years. Slope is the CDS spread

\footnotetext{
${ }^{9}$ Data on sovereign CDS premium cover 10 different maturities, ranging from one to 10 years, and are collected from Capital IQ. The data are available for the period from 2006.
} 
with 10 year maturity minus the CDS spread with one year maturity. Curvature is the difference between the CDS spreads with 10 year and five year maturities minus the difference between the CDS spreads with five year and one year maturities. For illustration, we depict the cross-sectional dispersion of sovereign-CDS-spread factors of the Euro-area countries (with and without GIIPS countries) in Figure 7. Dispersion is measured as the cross-sectional standard deviation of the CDS-spread factor in each month. The figure shows that the dispersion of all the CDS-spread factors is very small before year 2008 and increases after the US financial crisis. The dispersion among all Euro-area countries accelerates in the European financial crisis, with a notably larger rate than the dispersion among non-GIIPS countries. Although increasing in general, they peak in 2011, whereas the dispersions in slope and curvature, respectively, reach their peaks in the start of 2012 and towards the end of 2012. This reveals that the comovement of credit risk differs across maturities and suggests the need to delve into credit-risk term structure.

We report the parameters of the spatial correlation function for different latent factors and asset holdings in Table 4 . We demean $\sigma_{\mathrm{CDS}, t-1}$ to capture the average spatial correlation via the parameter $\rho_{0}$, which makes it comparable with the estimation of time-invariant $\rho$ values in the other parts of the study. The estimated $\rho$ values are all highly significant and show the same relative pattern as the time-invariant $\rho$ values in Table 2, but all are slightly lower than the corresponding values in Table 2. The lower values should be due to the fact that the sample, due to unavailability of the CDS spread data, starts in 2006 and the average degree of spatial dependence is lower in the later part of the sample. The estimated $\rho_{\mathrm{CDS}}$ are all negative and highly significant. This verifies that the degree of yield-factor comovement is negatively related to the differences in the countries' sovereign risk. As we illustrated in Figure 7, the dispersion of creditrisk factors has increased since 2008, even among non-GIIPS countries. Therefore, we can 
conclude that the divergence of the yield curve of the Euro-area countries (both with and without GIIPS countries) after 2008, illustrated in Figure 6, should be mostly related to the cross-sectional divergence in credit risk during this period.

\section{Conclusion}

We construct a spatial VAR model for yield curves by applying the spatial Durbin model to analyze the importance of cross-border asset holdings for yield-curve interactions among Euro-area countries.

Our results show a systematic spatial dependence in yield curve through cross-border long-term debt and bank lending, while the short-term debt and equity holdings appear unimportant. For all three latent factors of the yield curve, the spatial correlation parameters resulting from long-term debt and bank lending are statistically significant and are also above the $95 \%$ one-sided confidence interval of the spatial correlation parameters from a simulation study with 5000 randomly generated weight matrices. Further, we investigate the role of each country for the comovement of the yield curve within the Euro area. We find that France, Germany, Italy, and the Netherlands connect the Euro-area countries through cross-border investment and drive the comovement in interest rates.

Our study of the degree of integration over time shows that the degree of comovement in the Euro area declines considerably after 2008. This decrease may either indicate that the Euro bond markets become less sensitive to the shocks from other bond markets in the area, or that different Euroarea countries have reacted differently to outside shocks, such as the US financial crisis. To analyze this, we include US factors in our model. Our results show that the US effect cannot explain the Euro area divergence after 2008. Our further analysis shows that the divergence in the Euro area 
in the latter period largely reflects segmentation between GIIPS and non-GIIPS countries. The integration among non-GIIPS countries also declines, with a slower rate than that among all Euroarea countries.

A possible explanation for this divergence may be the divergence in the sovereign credit risks. We observe a substantial cross-sectional dispersion in sovereign CDS spread of the Euro-area countries after the US financial crisis, which is mostly due, but not limited, to the GIIPS countries. We extend, therefore, the model by defining a time-varying spatial correlation parameter as a function of the cross-sectional dispersion in the CDS spread. We find a strong negative relation between the degree of a yield factors' comovement and the dispersion in the countries' CDSspread term structure. 


\section{References}

Abbritti, M., Dell'Erba, S., Moreno, A., and Sola, S., 2013, Global Factors in the Term Structure of Interest Rates, IMF Working Papers 13/223.

Ang, A., and Longstaff, F. A., 2013, Systemic Sovereign Credit Risk: Lessons from the US and Europe. Journal of Monetary Economics 60, 493-510.

Ang, A., and Piazzesi, M., 2003, A No-Arbitrage Vector Autoregression of Term Structure Dynamics with Macroeconomic and Latent Variables, Journal of Monetary Economics 50, 745787.

Anselin, L., 2006. Spatial Econometrics, in: T. C. Mills and K. Patterson (Eds.), Palgrave Handbook of Econometrics: Volume 1, Econometric Theory. Basingstoke: Palgrave Macmillan, 901-969.

Antonakakis, N., and Vergos, K., 2013, Sovereign Bond Yield Spillovers in the Euro Zone during the Financial and Debt Crisis, Journal of International Financial Markets, Institutions and Money $26,258-272$.

Asgharian, H., Hess, W., and Liu, L., 2013, A Spatial Analysis of International Stock Market Linkages, Journal of Banking and Finance 37, 4738-4754.

Baele, L., Ferrando, A., Hördahl, P., Krylova, E., and Monnet, C., 2004, Measuring European Financial Integration, Oxford Review of Economic Policy 20, 509-530.

Bernoth, K., and Erdogan, B., 2012, Sovereign Bond Yield Spreads: A Time-Varying Coefficient Approach, Journal of International Money and Finance 31, 639-656.

Codogno, L., Favero, C., and Missale, A., 2003, Yield Spreads on EMU Government Bonds, Economic Policy 18, 503-532.

Costantini, M., Fragetta, M., and Melina, G., 2014, Determinants of Sovereign Bond Yield Spreads in the EMU: An Optimal Currency Area Perspective, European Economic Review 70, 337-349.

Dai, Q., and Singleton, K., 2000, Specification Analysis of Affine Term Structure Models, Journal of Finance 55, 1943-1978. 
Dewachter, H., and Lyrio, M., 2006, Macro Factors and the Term Structure of Interest Rates, Journal of Money, Credit and Banking 38, 119-140.

Diebold, F. X., Li, C., and Yued, V. Z., 2008, Global Yield Curve Dynamics and Interactions: A Dynamic Nelson Siegel Approach, Journal of Econometrics 146, 351-363.

Diebold, F. X., Rudebusch, G. D., and Aruoba, S. B., 2006, The Macroeconomy and the Yield Curve: A Dynamic Latent Factor Approach, Journal of Econometrics 131, 309-338.

Duffie, D., and Kan, R., 1996, A Yield-Factor Model of Interest Rates, Mathematical Finance 6, 379-406.

Ehrmann, M., Fratzscher, M., Gürkaynak, R. S., and Swanson, E. T., 2011, Convergence and Anchoring of Yield Curves in the Euro Area. Review of Economics and Statistics 93, 350-364.

Estrella, A. (2005). Why Does the Yield Curve Predict Output and Inflation? Economic Journal $115,722-744$.

Estrella, A., and Hardouvelis, G. A., 1991, The Term Structure as Predictor of Real Economic Activity, Journal of Finance 46, 555-576.

Estrella, A. and Mishkin, F. S., 1998, Predicting U.S. Recessions: Financial Variables as Leading Indicators. Review of Economics and Statistics 1, 45-61.

Evans, C., and Marshall, D., 2007, Economic Determinants of the Nominal Treasury Yield Curve, Journal of Monetary Economics 54, 1986-2003.

Hamilton, J. D. and Kim, D. H., 2002, A Re-examination of the Predictability of the Yield Spread for Real Economic Activity, Journal of Money, Credit, and Banking 34, 340-360.

Hördahl, P., Tristani, O., and Vestin, D., 2006, A Joint Econometric Model of Macroeconomic and Term-Structure Dynamics, Journal of Econometrics 131, 405-444.

Kelejian, H. H., Tavlas, G. S., and Hondronyiannis, G., 2006, A Spatial Modeling Approach to Contagion among Emerging Economies, Open Economies Review 17, 423-442.

Knez, P. J., Litterman, R., and Scheinkman, J., 1994, Explorations into Factors Explaining Money Market Returns, Journal of Finance 49, 1861-1882. 
Kozicki, S., and Tinsley, P. A., 2001, Shifting Endpoints in the Term Structure of Interest Rates, Journal of Monetary Economics 47, 613-652.

Laurent, R. (1988). An Interest Rate-Based Indicator of Monetary Policy, Economic Perspectives. Federal Reserve Bank of Chicago 12, 3-14.

LeSage, J. P., 1997, Bayesian Estimation of Spatial Autoregressive Models, International Regional Science Review 20, 113-129.

LeSage, J., and Pace, R. K., 2009, Introduction to Spatial Econometrics, Boca Raton: Chapman \& Hall/CRC.

Litterman, R. B., and Scheinkman, J., 1991, Common Factors Affecting Bond Returns, Journal of Fixed Income 1, 54-61.

Lund, J., and Christensen, C., 2005, Revisiting the Shape of the Yield Curve: The Effect of Interest Rate Volatility, Working paper, University of Aarhus.

Manganelli, S., and Wolswijk, G., 2009, What Drives Spreads in the Euro Area Government Bond Market? Economic Policy 24, 191-240.

Mishkin, F. S., 1990a, The Information in the Longer Maturity Term Structure about Future Inflation, Quarterly Journal of Economics 55, 815-828.

Mishkin, F. S., 1990b, A Multi-country Study of the Information in the Term Structure about Future Inflation, Journal of International Money and Finance 19, 2-22.

Nelson, C., and Siegel, A. F., 1987, Parsimonious Modeling of Yield Curves, Journal of Business 60, 473-489.

Rudebusch, G. D., and Wu, T., 2008, A Macro-Finance Model of the Term Structure, Monetary Policy and the Economy, Economic Journal 118, 906-926.

Solnik, B., and Roulet, J., 2000, Dispersion as Cross-Sectional Correlation, Financial Analysts Journal 56, 54-61.

Wu, T., 2006, Macro Factors and the Affine Term Structure of Interest Rates, Journal of Money, Credit and Banking 38, 1847-1875. 


\section{Table 1. Nelson-Siegel estimations}

Panel A of the table summarizes the yield data used in the estimation of the Nelson-Siegel model and the goodness of fit of the estimations, for 11 Euro-area countries and the US. The first row reports the total number of available maturities for each country, while the second to forth rows give the average, minimum and maximum number of maturities, respectively, used to estimate the model in each month for each country. The fifth row shows the percentage of the months with at least 5 available maturities. In the second part of this panel, we report the time-series mean of the monthly variance of the yields of different maturities for each country and the related fitting error variance from the Nelson-Siegel estimations. The last row of Panel A reports the time-series average of monthly $R$-squares from the Nelson-Siegel estimations. Panel B. of the table shows the summary statistics of the estimated yield factors, level, slope and curvature, for different countries. The factors are estimated based on the Nelson-Siegel model on monthly yields for government bills and bonds with all available maturities ranging from three months to 15 years. Data covers the period from December 2001 to December 2012.

Panel A. Summary of the data and the goodness of fit

\begin{tabular}{lccccccccccccc}
\hline & Aus. & Bel. & Fin. & Fra. & Ger. & Gre. & Ire. & Ita & Neth & Por & Spa & US \\
\hline \# of available mat. & 14 & 13 & 13 & 14 & 13 & 13 & 13 & 13 & 13 & 14 & 15 & 8 \\
Ave. \# of mat./month & 13 & 13 & 10 & 14 & 13 & 12 & 9 & 13 & 13 & 12 & 13 & 7 \\
Min \# mat./month & 10 & 12 & 6 & 13 & 12 & 4 & 6 & 12 & 11 & 10 & 12 & 5 \\
Max \# mat./month & 14 & 13 & 12 & 14 & 13 & 13 & 11 & 13 & 13 & 13 & 15 & 8 \\
\% with at least 5 mat. & 100 & 100 & 100 & 100 & 100 & 92 & 100 & 100 & 100 & 100 & 100 & 100 \\
\hline Yield variance & 0.526 & 0.662 & 0.448 & 0.637 & 0.485 & 10.896 & 2.159 & 0.923 & 0.542 & 2.657 & 0.909 & 0.878 \\
Fitting error variance & 0.018 & 0.010 & 0.013 & 0.016 & 0.015 & 1.100 & 0.078 & 0.019 & 0.011 & 0.151 & 0.015 & 0.019 \\
$R$-square & 0.888 & 0.952 & 0.919 & 0.939 & 0.930 & 0.930 & 0.897 & 0.956 & 0.944 & 0.949 & 0.952 & 0.927 \\
\hline
\end{tabular}


Table 1. Nelson-Siegel estimations (Continued)

Panel B. Summary statistics of the estimated yield-curve factors

\begin{tabular}{|c|c|c|c|c|c|c|c|c|}
\hline & & Mean & Stdev & Min & Max & Kurt. & Skew. & Autocor. \\
\hline \multirow{12}{*}{ Level } & Austria & $4.299^{* *}$ & 0.655 & 2.546 & 5.620 & -0.071 & -0.349 & $0.938^{* * *}$ \\
\hline & Belgium & $4.452^{* *}$ & 0.604 & 2.677 & 5.796 & 0.075 & -0.207 & $0.904^{* *}$ \\
\hline & Finland & $4.177^{* *}$ & 0.723 & 2.230 & 5.808 & 0.395 & -0.336 & $0.947^{* *}$ \\
\hline & France & $4.238^{* *}$ & 0.636 & 2.616 & 5.667 & 0.079 & -0.156 & $0.934^{* *}$ \\
\hline & Germany & $3.932^{* *}$ & 0.884 & 1.642 & 5.635 & 0.302 & -0.636 & $0.964^{* *}$ \\
\hline & Greece & $5.741^{\text {** }}$ & 1.792 & 3.686 & 11.659 & $2.727^{* *}$ & $1.748^{* *}$ & $0.959^{* * *}$ \\
\hline & Ireland & $5.541^{* *}$ & 1.578 & 3.470 & 10.249 & $1.273^{* *}$ & $1.258^{* *}$ & $0.961^{* *}$ \\
\hline & Italy & $4.971^{* *}$ & 0.710 & 3.666 & 7.220 & $0.728^{* *}$ & 0.674 & $0.933^{* *}$ \\
\hline & Netherlands & $4.156^{* *}$ & 0.784 & 2.096 & 5.666 & 0.165 & -0.663 & $0.945^{* *}$ \\
\hline & Portugal & $5.888^{* *}$ & 2.669 & 3.468 & 16.536 & $3.668^{* *}$ & $2.035^{* *}$ & $0.972^{* *}$ \\
\hline & Spain & $4.876^{* *}$ & 0.878 & 3.398 & 7.786 & 0.270 & 0.690 & $0.945^{* *}$ \\
\hline & US & $4.198^{* *}$ & 0.970 & 1.691 & 5.922 & $0.583^{\text {** }}$ & $-1.046^{*}$ & $0.943^{* *}$ \\
\hline \multirow[t]{12}{*}{ Slope } & Austria & $1.573^{* *}$ & 1.322 & -1.703 & 5.027 & -0.332 & -0.372 & $0.908^{* *}$ \\
\hline & Belgium & $2.313^{* *}$ & 1.223 & 0.015 & 4.539 & $-1.127^{* *}$ & -0.034 & $0.940^{* * *}$ \\
\hline & Finland & $1.183^{* *}$ & 1.070 & -1.661 & 2.952 & $-0.426^{*}$ & -0.660 & $0.937^{* *}$ \\
\hline & France & $2.153^{* *}$ & 1.018 & -0.096 & 4.032 & $-0.735^{* *}$ & -0.106 & $0.950^{* *}$ \\
\hline & Germany & $1.958^{* *}$ & 0.919 & -0.290 & 3.752 & $-0.438^{*}$ & -0.084 & $0.920^{* *}$ \\
\hline & Greece & $4.674^{* *}$ & 5.341 & -1.169 & 16.499 & 0.245 & $1.334^{* *}$ & $0.976^{* *}$ \\
\hline & Ireland & $3.165^{* *}$ & 3.305 & -1.284 & 15.013 & $1.782^{* *}$ & $1.307^{* *}$ & $0.950^{* *}$ \\
\hline & Italy & $2.816^{* *}$ & 1.546 & 0.362 & 6.547 & $-1.003^{* *}$ & 0.347 & $0.953^{* *}$ \\
\hline & Netherlands & $2.005^{* *}$ & 1.031 & -0.030 & 4.126 & $-0.688^{* *}$ & 0.011 & $0.945^{* *}$ \\
\hline & Portugal & $3.707^{* *}$ & 3.929 & -0.154 & 21.061 & $3.532^{* *}$ & $1.886^{* *}$ & $0.923^{* *}$ \\
\hline & Spain & $2.607^{* *}$ & 1.792 & -0.272 & 8.006 & -0.199 & 0.608 & $0.956^{* *}$ \\
\hline & US & $2.405^{* *}$ & 1.447 & -0.820 & 4.620 & $-0.899^{* *}$ & -0.435 & $0.955^{* *}$ \\
\hline \multirow{12}{*}{ Curvature } & Austria & $-4.239^{* *}$ & 2.714 & -10.933 & 0.772 & -0.389 & -0.151 & $0.904^{* *}$ \\
\hline & Belgium & $-3.481^{* *}$ & 2.167 & -8.639 & 0.451 & $-1.056^{* *}$ & 0.217 & $0.833^{* *}$ \\
\hline & Finland & $-4.766^{* *}$ & 3.098 & -11.755 & 0.294 & $-0.971^{* *}$ & -0.176 & $0.943^{* *}$ \\
\hline & France & $-3.487^{* *}$ & 2.185 & -7.106 & 0.571 & $-1.011^{* *}$ & 0.379 & $0.944^{* *}$ \\
\hline & Germany & $-2.979^{* *}$ & 2.058 & -6.495 & 1.209 & $-0.987^{* *}$ & 0.515 & $0.932^{* *}$ \\
\hline & Greece & $9.950^{* *}$ & 27.061 & -8.167 & 71.003 & $1.158^{* *}$ & $1.713^{* *}$ & $0.989^{* *}$ \\
\hline & Ireland & $-3.373^{* *}$ & 6.844 & -16.039 & 29.979 & $9.899^{* * *}$ & $2.706^{* *}$ & $0.620^{* *}$ \\
\hline & Italy & $-2.951^{* *}$ & 2.078 & -6.542 & 4.086 & $-0.566^{* *}$ & 0.382 & $0.826^{* *}$ \\
\hline & Netherlands & $-3.528^{* *}$ & 2.051 & -6.803 & 0.153 & $-1.091^{* *}$ & 0.484 & $0.928^{* *}$ \\
\hline & Portugal & $-1.845^{*}$ & 10.041 & -31.422 & 37.818 & $6.439^{* *}$ & $1.500^{* *}$ & $0.759^{* *}$ \\
\hline & Spain & $-3.075^{* *}$ & 2.021 & -8.895 & 0.488 & $-0.436^{*}$ & -0.036 & $0.750^{* * *}$ \\
\hline & US & $-3.455^{* *}$ & 2.596 & -7.427 & 1.682 & $-0.922^{* *}$ & 0.513 & $0.949^{* * *}$ \\
\hline
\end{tabular}


Table 2. Estimation results from the spatial Durbin model (SDM) with one spatial lag This table presents the estimated results of the panel data SDM model:

$$
\boldsymbol{f}_{k t}=\rho_{k} \boldsymbol{W}_{t} \boldsymbol{f}_{k t}+\boldsymbol{X}_{t} \boldsymbol{\beta}_{k}+\boldsymbol{W}_{t} \boldsymbol{X}_{t} \boldsymbol{\theta}_{k}+\boldsymbol{D} \boldsymbol{\alpha}_{k}+\boldsymbol{D}^{y} \boldsymbol{\tau}_{k}+\boldsymbol{\varepsilon}_{k t},
$$

where $\boldsymbol{f}_{k t}$ contains $N$ observations of the factor $k$ at time $t, \boldsymbol{X}_{t}$ is an $N \times K$ matrix of the lagged values of all factors, and $\boldsymbol{\beta}_{k}$ and $\boldsymbol{\theta}_{k}$ are the corresponding parameter vectors. $\boldsymbol{W}_{t}$ is the $N \times N$ spatial weight matrix. $\boldsymbol{D}$ is an $N \times N$ matrix containing a vector of ones and country dummies, and $\boldsymbol{\alpha}_{k}$ is an $N \times 1$ vector of the global constant and fixed-effect parameters. $\boldsymbol{D}^{y}$ is an $N \times(Y-1)$ matrix of year dummies, where $Y$ is the number of years, and $\boldsymbol{\tau}_{k}$ is the vector for year fixed effects. $\boldsymbol{\varepsilon}_{k t}$ is an $N \times 1$ vector of error terms. The estimations are based on monthly values for 11 Euro-area countries over the period from January 2002 to December 2012. The parameters marked with one asterisk are significant at the 5\% level and those with two asterisks are significant at the $1 \%$ level.

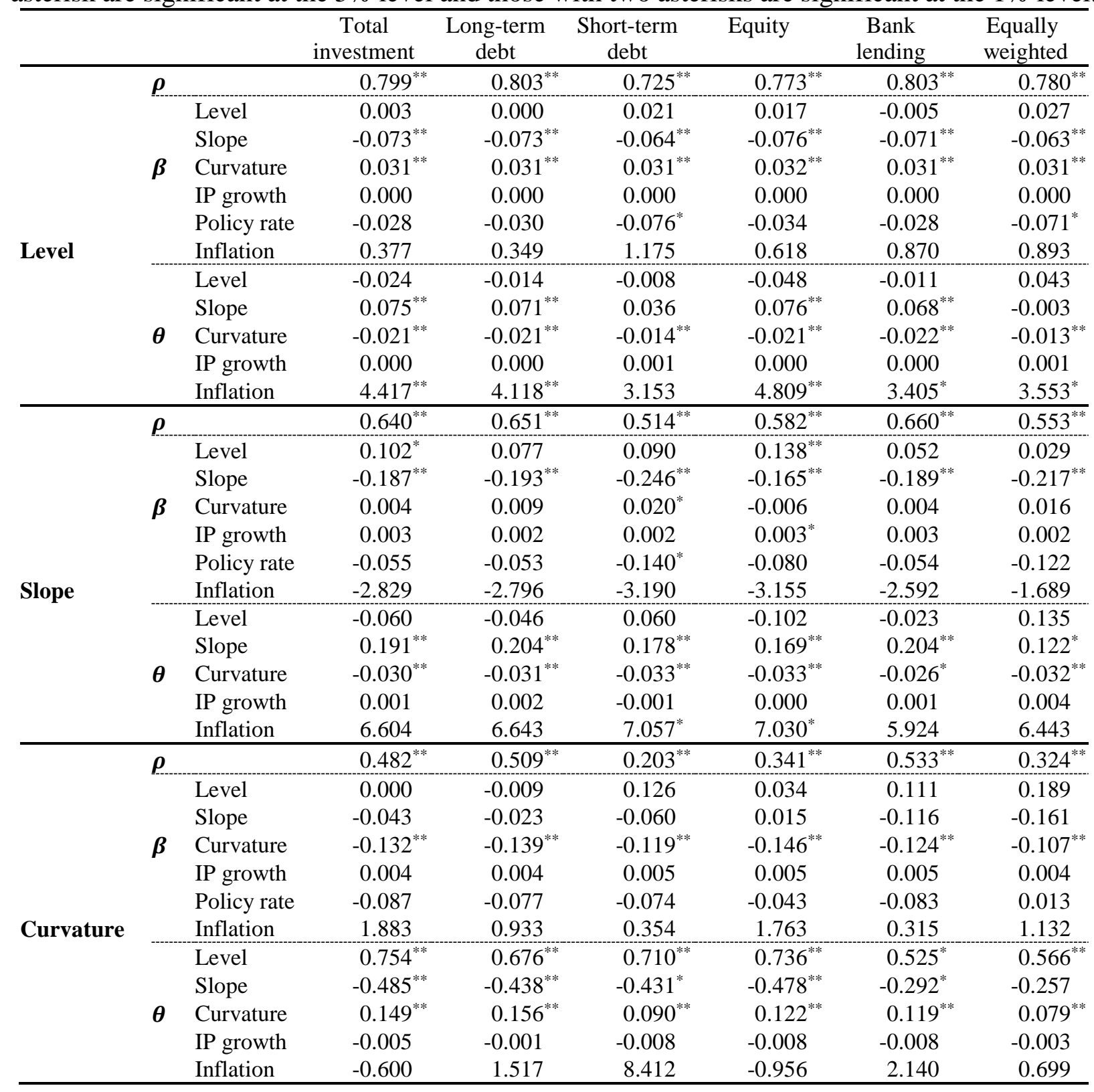


Table 3. Total spatial effects

The table shows the total (i.e., marginal) effect of a shock to the latent factor of each country averaged over time. The countries where shocks originate are in the columns of the table. The countries that receive the effects of the shocks are in the rows. The values of the effects are calculated according to equation (11). The spatial correlations are estimated from equation (10). The total cross-border portfolio investment is used as the closeness measure. The last row for each latent factor shows the average of the effects of each country on other countries.

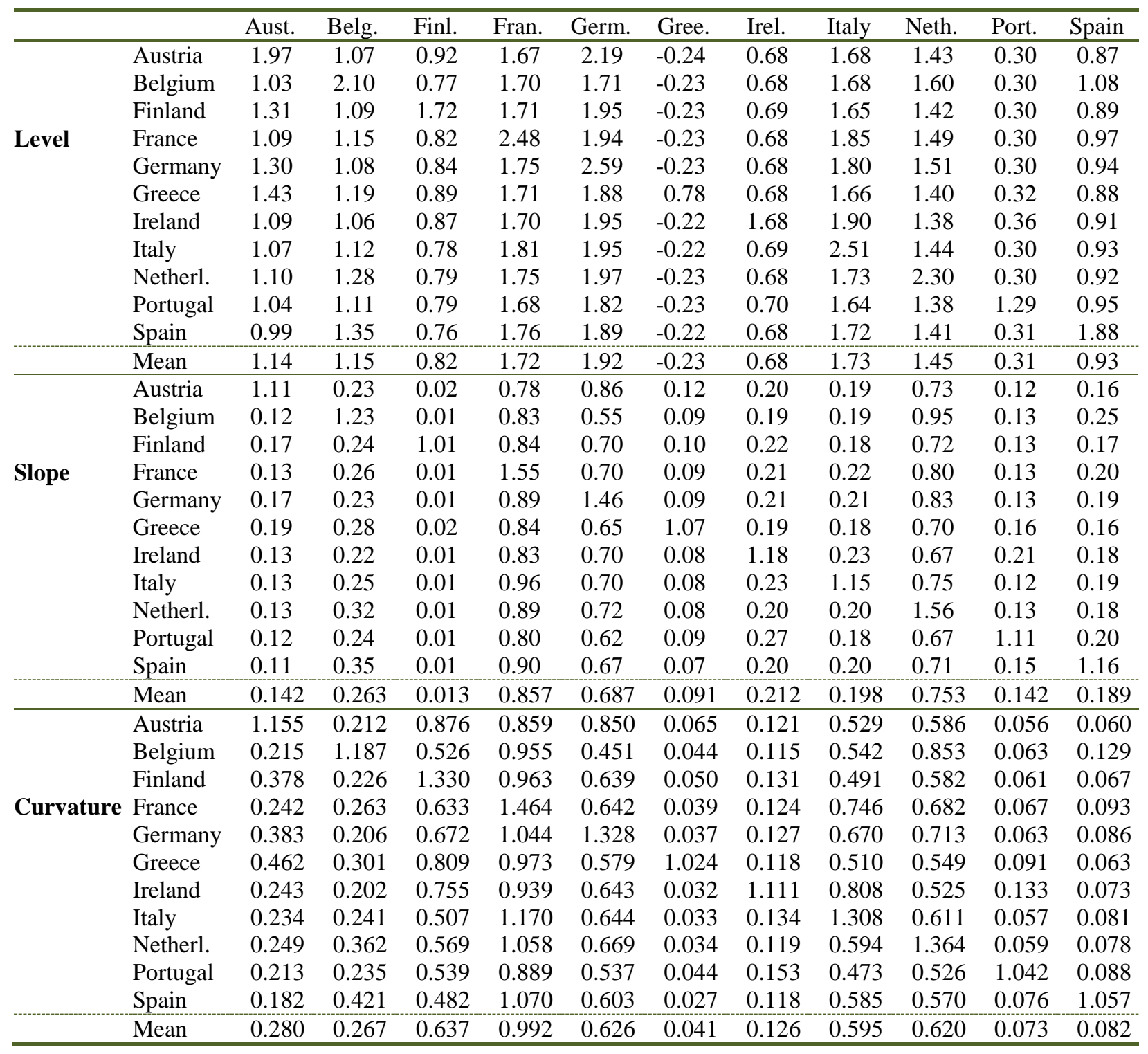


Table 4. Spatial correlation and the cross-sectional dispersion in sovereign CDS spread

The table presents the estimated $\rho_{0}$ and $\rho_{\mathrm{CDS}}$ in equation (15), which extends the model in equation (3) by allowing a time-varying spatial correlation parameter as a function of the cross-sectional dispersion in the term structure of sovereign CDS spread basis points: $\rho_{t}=\rho_{0}+\rho_{\mathrm{CDS}} \sigma_{\mathrm{CDS}, t-1}$. $\sigma_{\mathrm{CDS}}$ is the cross-sectional standard deviation of the sovereign CDS spread level, slope, and curvature, respectively, in the regression for yield-curve level, slope, and curvature. The estimations are based on monthly values for 11 Euro-area countries over the period from January 2002 to December 2012. The parameters marked with one asterisk are significant at the 5\% level, and those with two asterisks are significant at the $1 \%$ level.

\begin{tabular}{clccccc}
\hline & & $\begin{array}{c}\text { Total } \\
\text { investment }\end{array}$ & $\begin{array}{c}\text { Long-term } \\
\text { debt }\end{array}$ & $\begin{array}{c}\text { Short-term } \\
\text { debt }\end{array}$ & Equity & $\begin{array}{c}\text { Bank } \\
\text { lending }\end{array}$ \\
\hline \multirow{2}{*}{ Level } & $\rho_{0}$ & $0.740^{* *}$ & $0.739^{* *}$ & $0.618^{* *}$ & $0.703^{* *}$ & $0.733^{* *}$ \\
& $\rho_{\text {CDS }}$ & $-0.001^{* *}$ & $-0.001^{* *}$ & $-0.002^{* *}$ & $-0.001^{* *}$ & $-0.001^{* *}$ \\
\hline \multirow{2}{*}{ Slope } & $\rho_{0}$ & $0.516^{* *}$ & $0.519^{* *}$ & $0.435^{* *}$ & $0.510^{* *}$ & $0.527^{* *}$ \\
& $\rho_{\text {CDS }}$ & $-0.003^{* *}$ & $-0.003^{* *}$ & $-0.004^{* *}$ & $-0.004^{* *}$ & $-0.003^{* *}$ \\
\hline Curvature & $\rho_{0}$ & $0.421^{* *}$ & $0.424^{* *}$ & $0.353^{* *}$ & $0.413^{* *}$ & $0.420^{* *}$ \\
& $\rho_{\text {CDS }}$ & $-0.012^{* *}$ & $-0.011^{* *}$ & $-0.012^{* *}$ & $-0.013^{* *}$ & $-0.014^{* *}$ \\
\hline
\end{tabular}


Figure 1. Yield-curve latent factors and macroeconomic factors of the US and Euro-area countries The figure shows the changes in the estimated latent factors and the macroeconomic factors for the US as well as for the Euro-area countries with and without the GIIPS countries. The factors are estimated based on the Nelson-Siegel model on yield for government bills and bonds with all available maturities ranging from three months to 15 years. Data covers the period starting from December 2001 and ending in December 2012.

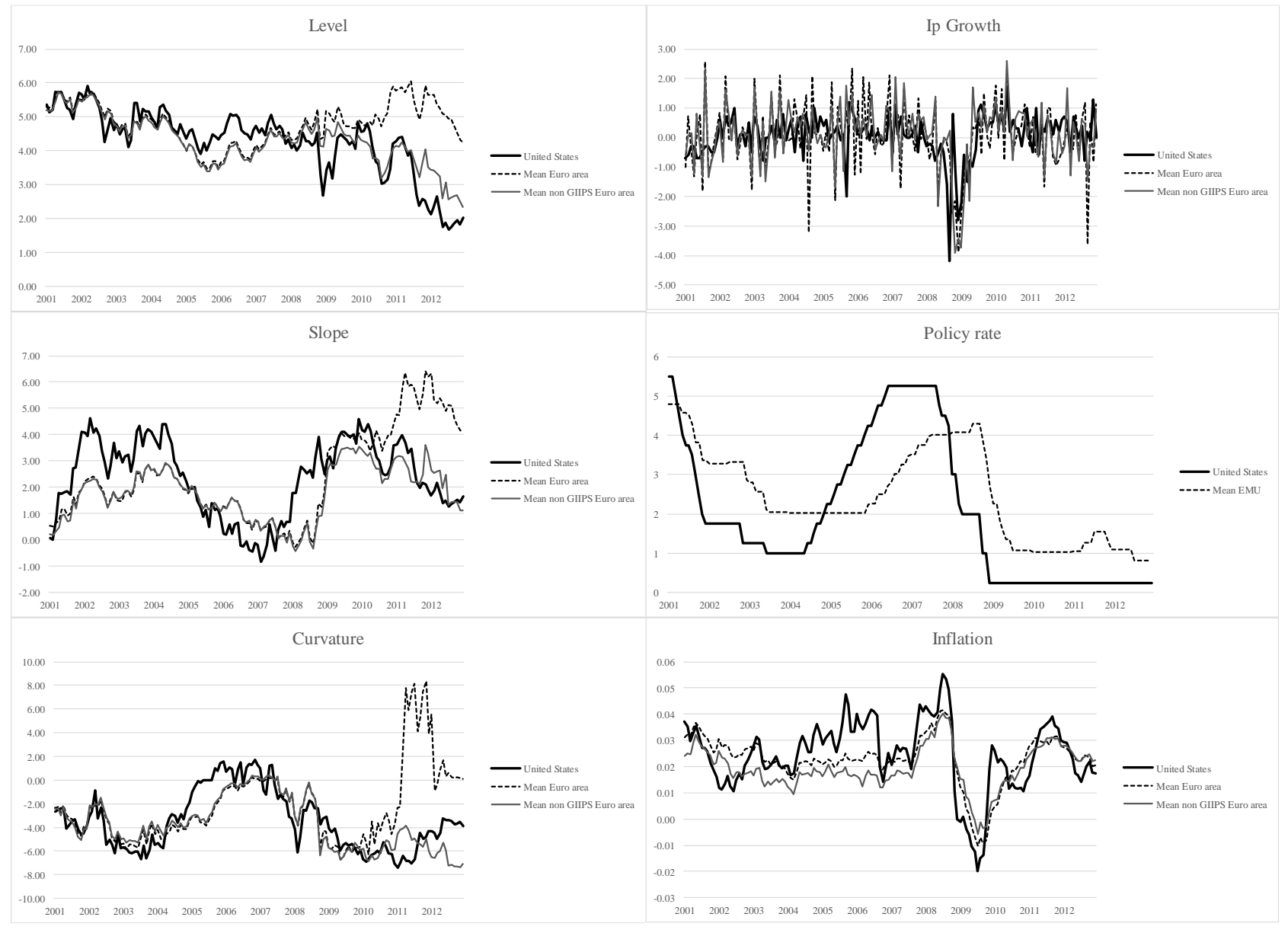


Figure 2. Estimated spatial correlations from the closeness measures compared with the empirical distributions of the spatial correlations

The figure compares the estimated values of the spatial correlation coefficients $\rho$ from our selected closeness measures (the dots) with those from randomly generated weight matrices. The estimated spatial coefficients are obtained from the panel data spatial Durbin model with one spatial lag and with country-specific effects and year dummies (equation 3). The estimations are based on monthly data covering 11 Euro-area countries over the period from January 2002 to December 2012. The spatial weight matrix is defined according to cross-border long- and short-term debts, equity investment and bank lending, as well as a matrix with equal weights. The lines show the $99 \%$ and $95 \%$ one-sided confidence interval of the empirical distribution of the estimated $\rho$ values from 5000 randomly generated spatial weight matrices.

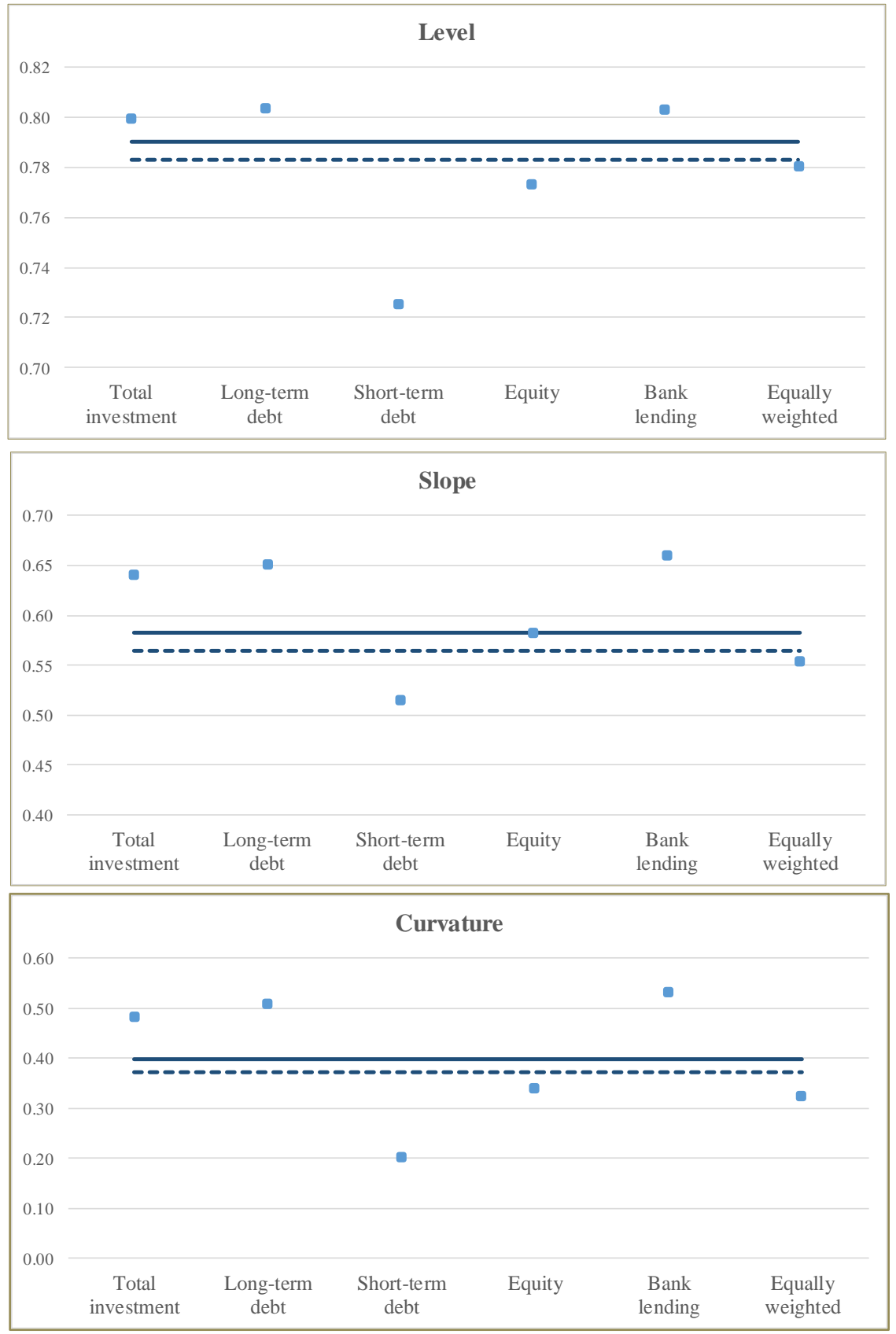


Figure 3. Asset holdings among Euro-area countries

The figure shows the total amount of cross-border asset holdings among the 11 Euro-area countries included in the sample over time. Data covers the period starting January 2001 and ending December 2011.

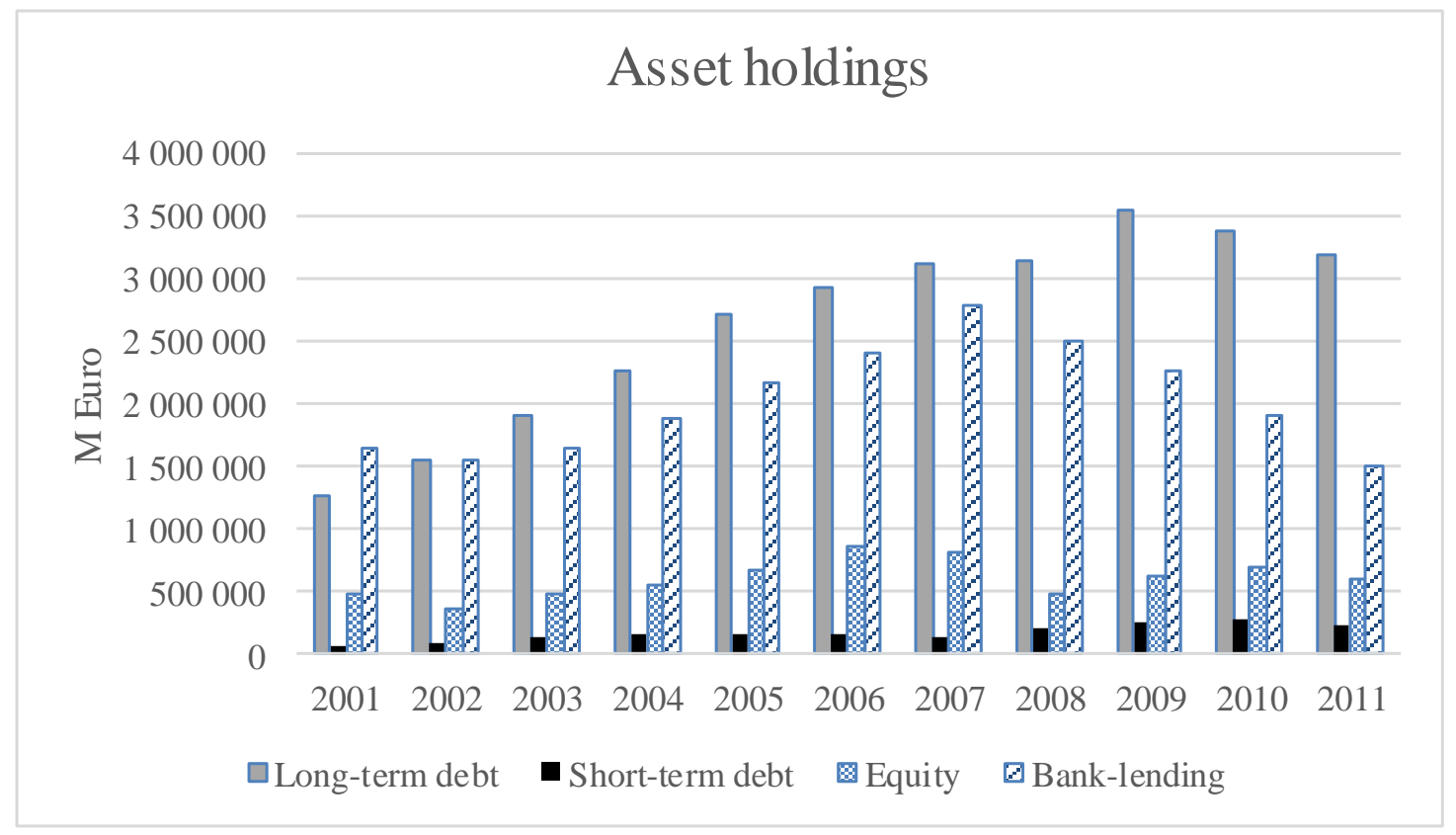


Figure 4. Comparing implied yields to maturities with actual data

The figure shows the mean absolute error (MAE) obtained by comparing the model implied yields to the actual data, as well as the correlation between the two series. We use the reduced form of the spatial regression model to obtain the implied factors, which then are used in the Nelson-Siegel equation to calculate implied yields. The figure shows the results for two selected weighting matrices, i.e. equally weighted and bank lending, and two different maturities, five and 10 years.

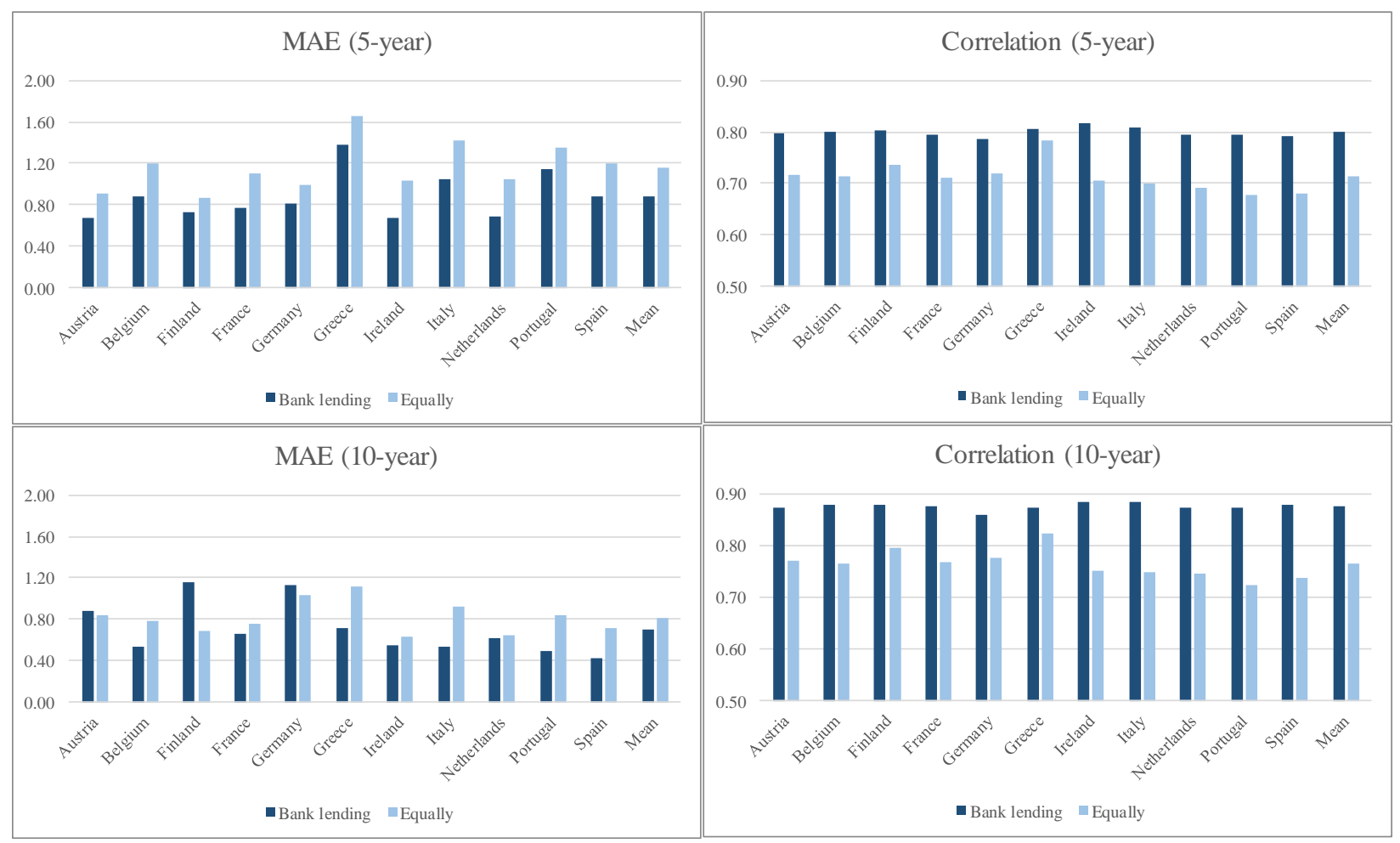


Figure 5. Cross-border investment and spatial effects

For each country, edges point to three closest countries in terms of the volumes of total bilateral investment in the period from January 2001 to December 2011. The size of the node for each country indicates the average spatial effect of the country's level factor on the Euro area shown in Table 3.

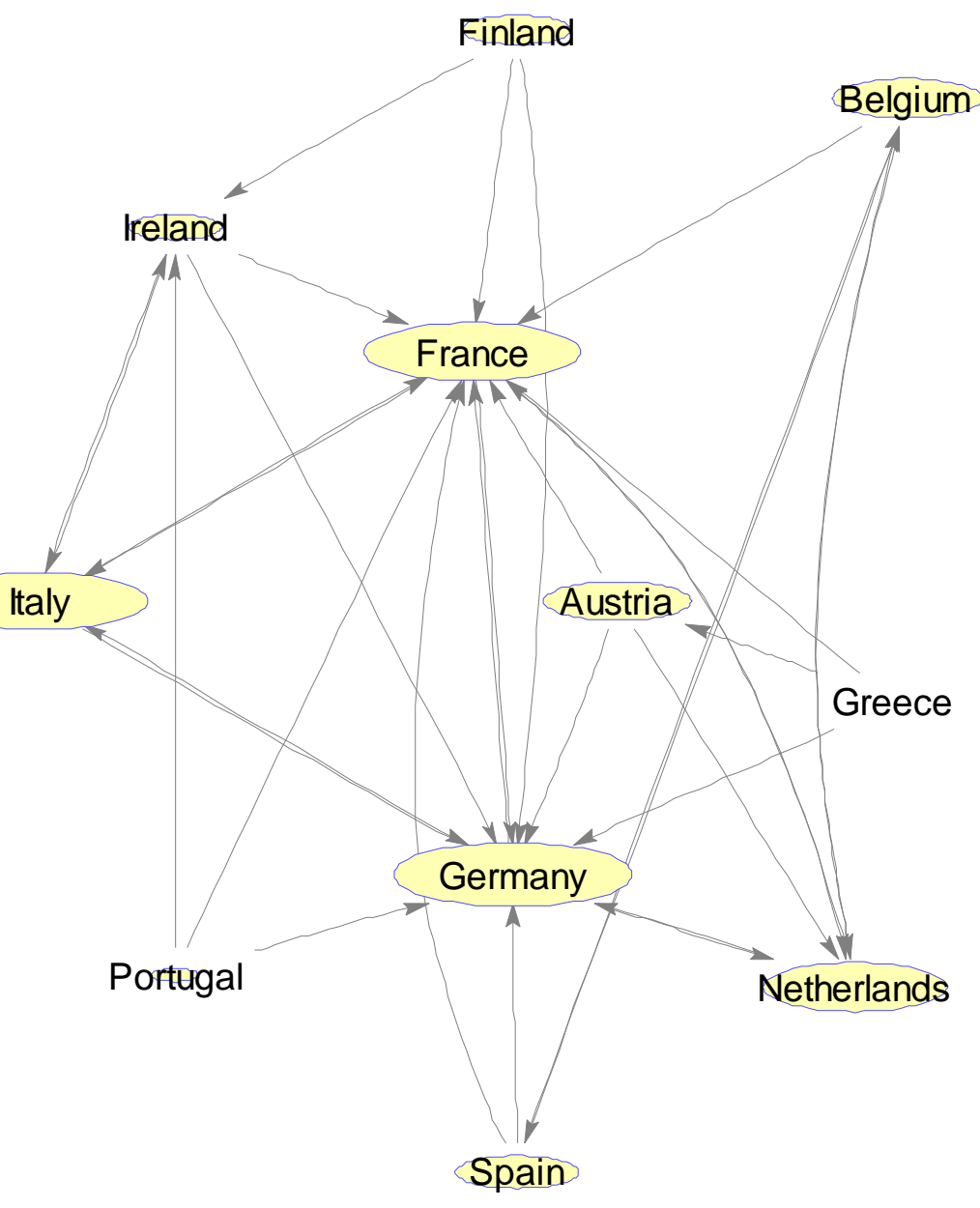




\section{Figure 6. The estimates of spatial correlation coefficient}

The figure presents the yearly estimated values and 95\% confidence intervals of the spatial correlation coefficient $\rho$ of Euro-area countries in each year from January 2002 to December 2012. The dots show each estimate of $\rho$. The intervals are the 95\% confidence interval of the estimated $\rho$ values. The graphs on the left and right show $\rho$ values estimated from equation (3) based on the sample with 11 Euro-area countries and the sample of non-GIIPS Euro-area countries, respectively. The graphs in the middle show the $\rho$ values for 11 Euro-area countries estimated from equation (12) based on the sample including the US. The spatial weight matrix is defined according to the total cross-border investment in all cases.

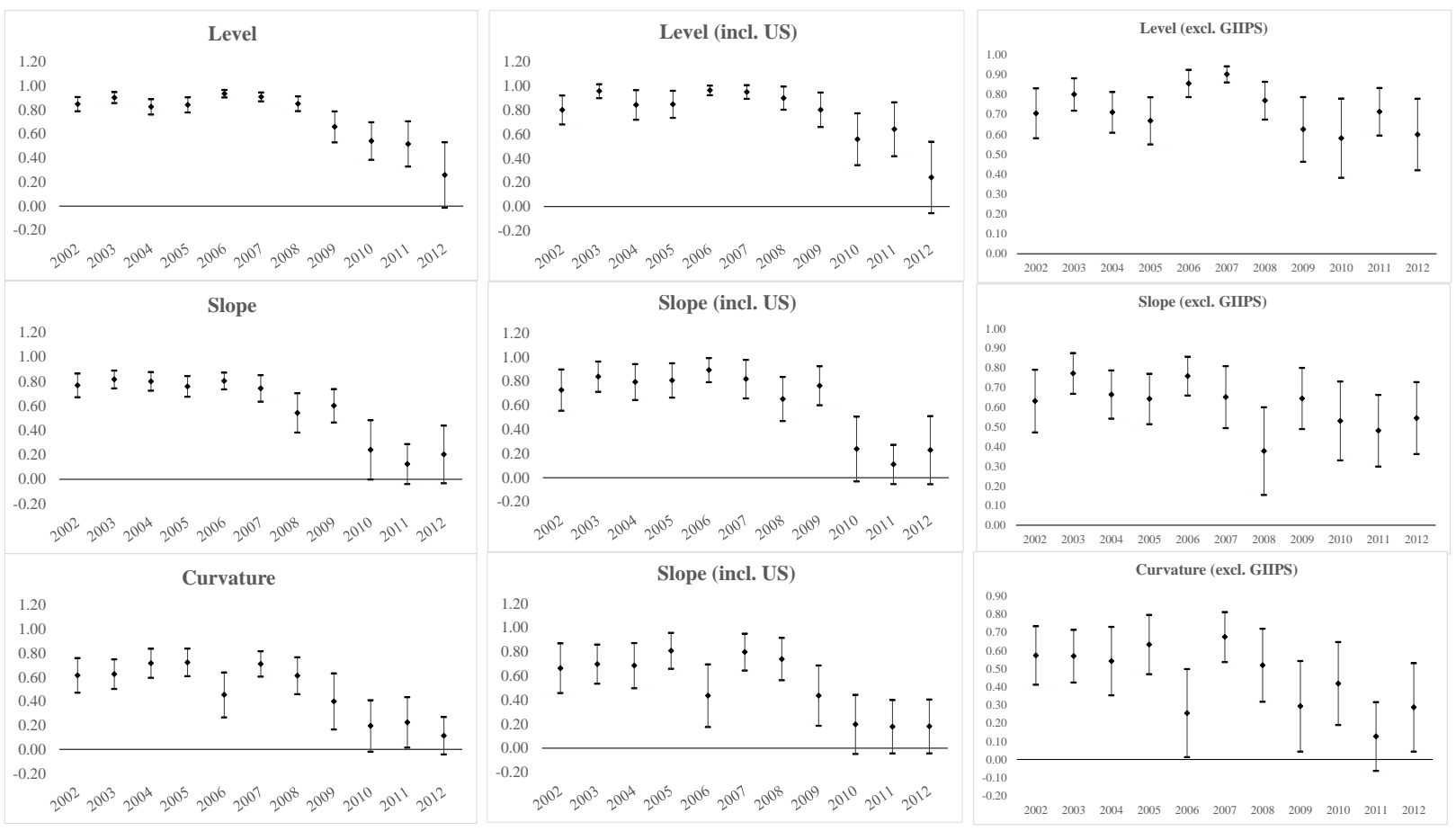




\section{Figure 7. Dispersion of CDS-spread factors}

The figure shows the cross-sectional dispersion of the level, slope and curvature of sovereign credit default swap (CDS) spread (in basis points) of 11 Euro-area countries (with and without GIIPS countries).
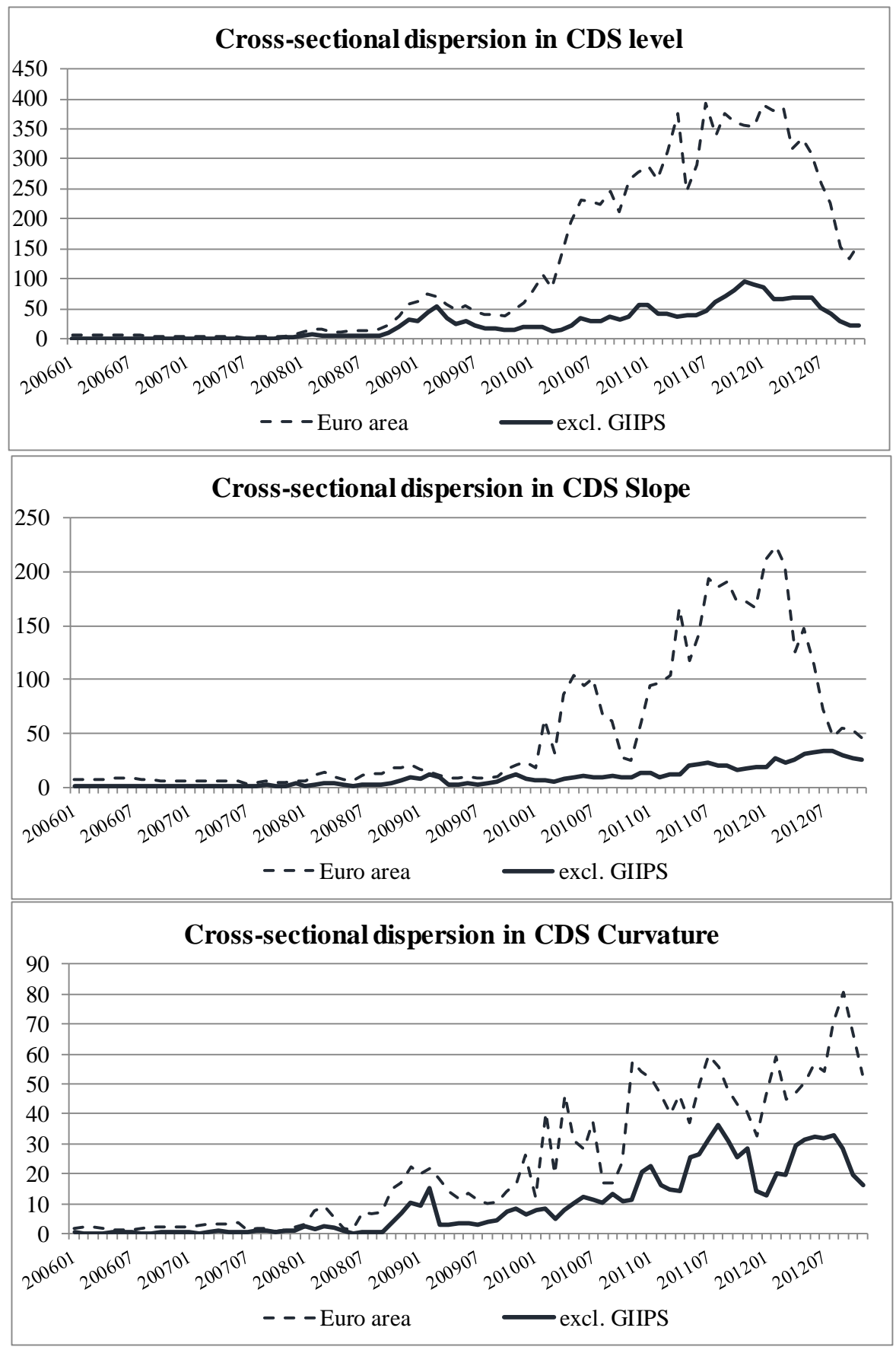